\title{
Promoting the Emergence of Team Flow in Organizations
}

\author{
Jef J. J. van den Hout ${ }^{1,2}$ (D) Orin C. Davis ${ }^{3,4}$ \\ Accepted: 22 September 2021/Published online: 13 October 2021 \\ (c) The Author(s) 2021
}

\begin{abstract}
An important question in the field of team research is how teams can optimize their collaboration to maximize their performance. When team members who are collaborating towards a common purpose experience flow together, the team, as a performing unit, improves its performance and delivers individual happiness to its members. From a practical point of view, it is relevant to know how team flow experiences arise within professional organizations. The aim of this study is therefore to get more insight into the how the elements of team flow emerge. We conducted interviews with team members, business leaders, and team experts, and in addition a survey with team members. The results provide confirmation of the existing research on team dynamics, flow, group and team flow and indicate that a collective ambition, professional autonomy, and open communication must be deliberately and carefully cultivated to set the stage for the other team flow prerequisites and thence for team flow to emerge.
\end{abstract}

Keywords Team flow $\cdot$ Work teams $\cdot$ Flow $\cdot$ Optimal experience $\cdot$ Team effectiveness $\cdot$ High performance teams

Jef J. J. van den Hout jefvandenhout@gmail.com

1 School of Industrial Engineering, Eindhoven University of Technology, Eindhoven, The Netherlands

2 Flow Concepts, Tilburg, The Netherlands

3 Quality of Life Laboratory, New York, NY, USA

4 New York University, New York, NY, USA 


\section{Introduction}

An important question in the field of team research is how teams deliver optimal performance. We know a lot about the factors that influence the effectiveness of teams at work in organizations, including group composition, cohesiveness, goal setting, and motivation, which can also vary by type of team or autonomous work group (Guzzo \& Dickson, 1996; Hackman \& Wageman, 2005; Katzenbach $\&$ Smith, 1993). Findings from these studies provide strong support for the value that teams contribute to organizational effectiveness and specify the basic conditions needed to support an effective team. But, the literature offers surprisingly little insight into the nuances of the circumstances and interventions that have allowed some organizations to make optimally effective and efficient use of their teams where others have floundered.

One of the key factors that has been shown to contribute to high performance is flow (Landhäußer \& Keller, 2012). Flow is a subjective experience during which people report performing at their best (Nakamura \& Csikszentmihalyi, 2002). The defining feature of flow is intense experiential involvement in moment-tomoment activity such that engaging in the activity feels effortless. One of the primary benefits of this experience is that it promotes an intrinsic desire to seek greater levels of skill and corresponding challenges, which in turn means producing higher-level work (Csikszentmihalyi et al., 2005).

Extending flow from individuals to teams, researchers have codified the construct of team flow, defined as "a shared experience of flow during the execution of interdependent personal tasks in the interest of the team, originating from an optimized team dynamic and typified by seven prerequisites and four characteristics" (see van den Hout \& Davis, 2019, for a review). Based on an extensive literature review (Van den Hout et al., 2018) on flow and team dynamics, interview data, and survey data, they suggest (Fig. 1) that team flow starts with the establishment of a collective ambition. From this collective ambition, the team sets the other six prerequisites for team flow, which are: an audacious team goal, open communication, aligned personal goals, high skill integration, safety, and mutual commitment. It is very often necessary to go from the collective ambition to start building the audacious team goal and open communication before starting to build out the other four prerequisites, but the prerequisites do reinforce each other in a virtuous cycle (as in Fig. 1). Once in place, the prerequisites allow for the experience of the characteristics of team flow, which are: a sense of unity, a sense of joint progress, mutual trust, and holistic focus (van den Hout, 2016; van den Hout et al., 2018; van den Hout et al., 2017, 2019). In turn, these characteristics add fuel to the collective ambition, which reinforces the infrastructure of the team flow experience and keeps the team wanting to reconvene (cf. van den Hout \& Davis, 2019).

While the prerequisites and characteristics of team flow have been ascertained and validated, it remains unclear exactly how each of these elements arises within the team dynamic and how they interact with each other. Thus, the purpose of this study is to further explore the process of how the prerequisites and characteristics 


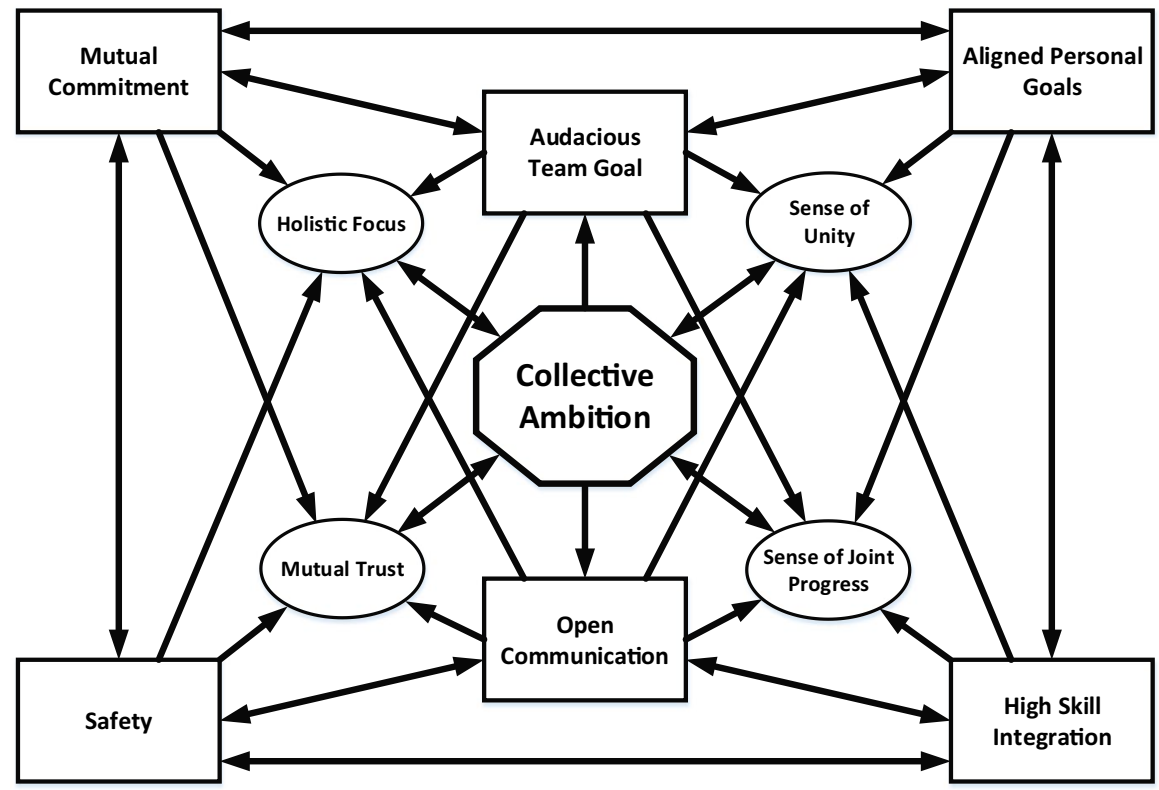

Fig. 1 The team flow model (van den Hout \& Davis, 2019)

of team flow come into being. We build on existing team flow theory without making explicit assumptions about how it will be applied in different kinds of work teams. Specifically, we pursue a grounded research strategy to develop a perspective on the nature of how the prerequisites and characteristics emerge in our chosen empirical contexts. Our goal is to enrich the theories about team flow with descriptions of team flow experiences and descriptions of the processes by which teams have achieved those experiences in real-world contexts. Specifically, we describe examples of how real work teams and business teams have achieved team flow, which we distill into the following pair of research questions: (1) "Through which processes does team flow emerge within professional organizations?" (2) "How could we help teams within professional organizations to achieve team flow?".

The process of team flow emergence is an interesting phenomenon in its own right, especially because research has highlighted its use as a management tool for diagnosing and/or improving team (dys)function (van den Hout \& Davis, 2019). With the addition of insight that elucidates the dynamics underlying team flow and its emergence, it would become more possible to develop a practical, step-by-step guide for fostering team flow.

In this article, we will start with a brief overview of team flow theory (for a more extensive review, see Van den Hout et al., 2019; Van den Hout \& Davis, 2018, 2019), then present the qualitative study in which we report on data collected from interviews with team members and team experts. These descriptions will increase our understanding of the emergence of team flow and how to use interventions to create environments in which it can be sparked. The findings from this study can be 
used to inspire future research on protocols that can observe and analyze the extent to which any given work environment supports the emergence of team flow. Our study delivers in-depth insights into the relations between the prerequisites and characteristics of team flow that we can use to develop a model of team flow for practical use, as well as suggestions for how an environment could be fostered where team flow is more likely to occur. In the discussion section, we expand on our key findings (insights) and take a broader look at the implications of the research for organizational theory and management practice.

\section{Theoretical Background}

\subsection{A Brief Review of Team Flow Theory}

Team flow is considered to be a function of shared experiences of flow during the execution of interdependent personal tasks in the interest of the team and comprises three core aspects: (1) individual team members together share the experience of flow by executing their interdependent tasks; (2) the team members deriving flow from the team dynamic, which is structured by seven team flow prerequisites: a collective ambition, a common goal, aligned personal goals, high skill integration, open communication, safety, and mutual commitment; and (3) team members sharing a dynamic that reflects a collective experience of flow defined by four specific characteristics: a sense of unity, a sense of joint progress, mutual trust, and holistic focus (Van den Hout \& Davis, 2019; Van den Hout et al., 2018; cf. Pels et al., 2018 for additional theoretical discussions, which we also referenced in van den Hout \& Davis, 2021 [cf. Van den Hout \& Davis, 2018]).

\subsection{Prerequisites of Team Flow}

Seven prerequisites are identified that foster the flow experiences of individual team members within the team context. As noted above, the collective ambition is the reason team members come together and the reason they feel connected to each other. This raison d'être serves as the foundation for the other six prerequisites. It helps the team set a clear and meaningful common goal that is shared by all team members (Locke \& Latham, 2006; O'Leary-Kelly et al., 1994; Sawyer, 2007). Team members contribute to the achievement of the common goal by setting aligned personal goals that are clearly defined, meaningful, proximal, and specific. This combination of individual- and team-level goals clearly shows the division of labor in the team and promotes growth and development in the individual team members (Locke \& Latham, 2006; Nakamura \& Csikszentmihalyi, 2009; O’Leary-Kelly et al., 1994). During task distribution, all team members either select or are assigned one or more challenging tasks or roles that suit their preferences, talents, knowledge, and skills (Katzenbach \& Smith, 1992; Salas et al., 2008), which in turn fits the challengeskill match element of individual flow (cf. Abuhamdeh \& Csikszentmihalyi, 2009). Therefore, the aligned personal goals provide high skill integration by playing to 
each team member's strengths. In this way, individual abilities are optimally utilized and combined to create a synergistic collaboration. Open communication supports team members' (tacit) knowledge about their contributions to the team (cf. Sawyer, 2007), and entails the provision of clear, constructive, and encouraging feedback on team members' personal tasks, the joint team task, and the process of collaboration. This real-time feedback not only promotes flow experiences (Csikszentmihalyi, 1996), but helps team members coordinate their efforts towards achieving the common goal in the most efficient and effective way (Guzzo \& Salas, 1995). Another critical element underpinning team flow is the safety to perform one's task as one sees fit in order to serve the interests of the team, with an implicit belief that it is safe to take risks as needed and that the team will not embarrass, reject, or punish good-faith efforts and communications (cf. Edmondson, 1999). Failure necessarily remains a possibility, however, because the goals are challenging and to achieve them a team needs to integrate high skills (cf. Sawyer, 1999). Safety within the team environment decreases team members' worries about the performance on their immediate tasks and promotes reciprocal trust. Concordant with this trustbased safety, team flow also requires that teammates engage with each other in ways that foster devotion and dedication to the team's desired common goal. This mutual commitment involves task-oriented coaching, holding oneself and others accountable, and taking responsibility as relevant in order to adapt one's work to the team's requirements and integrate one's activities with the common activities while causing the least possible disruption to others (Bardram \& Hansen, 2010; Dourish \& Bellotti, 1992; Schmidt, 2002). In many ways, mutual commitment is a vital part of cooperation and focus and therefore even a prerequisite for smooth cooperation. Everyone knows what the goals and the processes are, and instead of distracting each other, everyone is fully engaged in interdependent tasks.

The prerequisites for team flow foster an environment conducive to joint flow experiences in teams. Before we explore in detail how to create circumstances that foster such an environment, we will first describe the characteristics of team flow. The characteristics describe how team members experience the phenomenon of team flow and could therefore also function as indicators of the team flow experience.

\subsection{Characteristics of team flow}

When a team experiences team flow, it shares a number of team-level constructs called characteristics of team flow (van den Hout et al., 2018). The first of these is a sense of unity, a shared feeling that the team members form a unit together by expressing the collective ambition of the team (van den Hout \& Davis, 2019). This feeling contains cohesion (Widmeyer et al., 1986, p. 3), a loss of reflective selfconsciousness with fellow team members (cf. Csikszentmihalyi, 1997; Snow, 2010), and a blending of egos (Sawyer, 2007). The feeling of unity is partly the result of setting aligned personal goals that each contribute to the common goal, which in turn is derived from the collective ambition. Second, there is mutual trust, the shared feeling of trust that allows joint tasks to be accomplished together (cf. Gully et al., 2002) and team members to be vulnerable to the actions of their fellow team 
members (cf. Mayer et al., 1995). This feeling arises because open communication incites people to feel safe to act (without fear of failure or unnecessarily judgmental criticism for errors or differences of opinion) and ensures that they know exactly how well they are doing thanks to clear and immediate feedback. Thirdly, team members have a sense of joint progress, a shared feeling of progressing towards the team's goals together in close cooperation. This feeling arises because people communicate openly about the team's progress towards the common goal and everyone's contributions to that progress (cf. Amabile \& Kramer, 2011). Because of this open communication, everybody knows exactly how they are doing and which individual and joint actions their team-level and personal goals will be required next. Finally, there is holistic focus, or the realization that there exists among the team members a collective consciousness that is intent on pursuing the collective ambition, resulting in a shared focus upon team members' cooperation and the achievement of their goals (cf. Hamilton \& Hurford, 2007; Isaksen \& Lauer, 2002).

The degree to which the characteristics for team flow are present determines whether and to what extent team flow occurs. Team flow occurs when all team members are experiencing the four characteristics by means of a team dynamic created by the seven prerequisites. The experience can differ in its intensity and duration, however, ranging from a theorized micro-level of team flow (cf. Davis, 2010) to "full team flow," occurs when all of the team members experience the characteristics at an optimal level for a given period of time. Research has shown that team flow is positively correlated with individual outcomes like general and current level of happiness and individual flow experiences, as well as team-level outcomes like team positivity and team performance (Van den Hout et al., 2019). For the creation of an environment conducive to team flow, it would be useful to delineate the process[es] by which the prerequisites of team flow lead to the experience of its characteristics, and this is the basis for our study.

\section{Methods}

\subsection{Exemplifying Quotes of the Emergence of Team Flow}

As we strive to elaborate and build on the existing theoretical ideas, aiming to refine their concepts, relations, and explanatory limits, we use grounded theory to guide qualitative data gathering (Lee et al., 1999; Locke, 2001; Vaughan, 1992). We followed an inductive research design, starting with a literature review on (group) flow theory and team dynamics, and using it to guide the creation of a semi-structured interview and online survey. We confirmed face and content validity of the interview questions using both the literature and a panel of experts who are established researchers in the field (M.C.D.P. Weggeman,E. J.M.P. Gevers, B. Walrave \& A.C. Bontekoning). We first conducted five semi-structured interviews (with 1-2 team members in each interview) from two different mental health care organizations, and 10 with team experts to explore the range of perspectives on how the prerequisites of team flow appear at the team level and how they relate to the emergence of the characteristics and outcomes. All of these interviews were roughly $1.5 \mathrm{~h}$ in length 
and transcribed by a graduate student working for the first author, with transcripts ranging in length from 2 to 13 pages (average 6). Four additional interviews were conducted by the first author, one of which was transcribed in its entirety by the first author (4 pages) and the others of which were covered by notes (ranging from 1 to 3 pages in length [average 2]). In addition, we gave 25 teams from 15 organizations representing 14 industries an online survey with three open-ended questions to collect exemplars of team flow experiences, obstacles, and fulcra for team flow. An additional goal guiding our data collection was to better understand how best to create the prerequisites of team flow, how they interrelate, and how they affect the characteristics of team flow experience itself and the outcome.

The interviewed team members were not specifically briefed on the definition of individual flow and the definition of team flow (as above). We began by asking participants to describe critical events where team collaboration was optimized and/or where team collaboration ran smoothly while the team was performing a challenging common task. They were then posed a question to help clarify their description of the event. We also asked participants to describe an event where the team got stuck and the collaboration no longer worked. Table 1 in the appendices contains the (translated) interview format with the questions used During the interviews, questioning focused on the phenomenon of achieving flow together. Several quotes from the team member's interview reports were selected in Table 2 as exemplars of the experience of team flow, the prerequisites, or the characteristics.

As we were not able to interview every team member, the online survey allowed us to expand the sample size. Participants in the survey were instructed on the concepts of flow and team flow by means of a presentation before taking part. The online survey contained the following questions: What keeps you from achieving flow during the performance of your task for the team; What allows you to achieve flow during the performance of your task for the team; Suggestions for achieving more flow in our team on this specific moment are...; Can you give an example of a moment of team flow? The responses $(\mathrm{N}=235)$ were coded by three independent raters assessing whether the responses included any of the impediments to team flow (van den Hout \& Davis, 2019) on the first question, and components of team flow in the second, third, and fourth questions. The fourth question yielded too few clear results for reliable analysis, and was excluded. In addition, several quotes from the surveys among team members were also selected in Table 2 as exemplars of the experience of team flow, the prerequisites, or the characteristics.

The goal for the team expert interviews was to determine whether they acknowledge the proposed prerequisites for team flow and whether, based on their expertise, they could offer detailed explanations for those prerequisites. During these interviews, the interviewer explained the concepts of flow and team flow by providing their definitions and discussing the prerequisites and characteristics of team flow. For each prerequisite or characteristic, the construct was presented and the expert was then asked about the construct's importance and how it might be realized in a team. Several quotes from the surveys among team experts were selected in Table 3 as exemplars of their takes on team flow in general, the prerequisites, or the characteristics. 
After repeated readings of the interview transcripts and the answers collected with the online survey, quotations were selected that address our research question by looking for concepts that are related to teamwork (e.g., trust, communication, safety). As the questions pertained to team situations, almost every sentence was relevant in some way. The selected quotations were then categorized and labelled according to Glaser and Strauss' (1967) principles of concept discovery. Concept discovery refers to the strategic process of moving from data to abstract categories (Glaser, 1978; Glaser \& Strauss, 1967), labels (Turner, 1981), or concepts. In selecting the quotations, our focus was on finding statements that constitute practical examples of the prerequisites and characteristics and can be used to find possible relationships between them. To that end, three research assistants separately categorized the quotations (sentence by sentence) by whether they discussed prerequisites, characteristics, or team flow as a whole. Based on the results, we found narrative descriptions of how team flow emerges across a variety of situations, which provides additional support for our extant model of team flow. In doing so, we used theoretical sampling interspersed with writing theoretical memos until data saturation was achieved, with analysis performed based on open, axial, and selective encoding (Charmaz, 2014; Glaser \& Strauss, 1967). We worked this phenomenological process, using Morse's (1994) strategies of comprehension, synthesizing, theorizing, and recontextualization. To conceptualize the process of team flow emergence, we analyzed the data line by line while asking the following questions: "What are the participants describing? What was important for activating the team flow experience? Did they have this experience at the team level? Which [team flow] elements were present at that moment? What were the benefits of this specific experience?" This method of constant comparison was used to re-examine the data against the emerging categories and their related characteristics (Glaser \& Strauss, 1967).

\section{Results}

Table 1 in the appendices presents the 89 quotations selected from the team member interview reports or team member survey data, and Table 2 presents the 51 quotations selected form the team experts' interviews, along with information about which team and/or organization the quote came from. The team members in this study work in a diverse array of organizations, including a childcare provider, a municipality, an engineering agency, a high school, a healthcare organization, a mental healthcare organization, and a consulting firm (which makes generalization across industries all the more feasible). Grouping the quotes makes it possible to conduct an analysis for the features of each of the prerequisites and characteristics. To that end, the quotes were grouped into 12 categories: one for general aspects concerning team flow theory, and eleven more for each of the elements of team flow.

In addition, we conducted 12 semi-structured interviews with established practitioners and researchers who have expertise in teamwork. These were people who have successfully coached or supervised teams in the field, including organizational consultants, business team coaches, business leaders, and business team leaders. 
Collectively, they represent a diverse group of professionals who could present a broad range of perspectives on the team flow phenomenon.

Below, we will describe the main patterns from our analyses of the quotations (see Table 1 in the Appendixes). While the appendix contains the full set of quotes, we selected a few illustrative quotes to highlight key points in the text. In order to answer the research questions for the study, we will split those results into general aspects concerning team flow theory, results that address the importance of the collective ambition to team flow, and important interrelations between the elements of team flow and assess how the relationships visible in the Team Flow Model are exemplified by the participants of study.

The results of the online survey (Tables 4 and 5) provided additional confirmation that the impediments and elements of team flow actually occur in a variety of business settings, with miscommunication being the most common impediment to team flow ( $\sim 8 \%$ of respondents), and its inverse, open communication ( $\sim 9 \%)$, being the most common reason why teams experience team flow. Open communication was also the second most common recommendation for promoting team flow $(15 \%$ of respondents), second only to having a common goal (20\%). As people are unaccustomed to thinking about flow experiences (given how rare they are [cf. Csikszentmihalyi, 1997]), and there are many categories into which a short free-response can fall, these lower numbers are not actually surprising. Interrater reliability (Fleiss's Kappa) was at acceptable levels and statistically significant (i.e., the agreement was not due to chance) for all three questions. For the first question (impediments to team flow), there were three raters, 231 responses, and $\kappa=0.33$ (95\% CI $0.31-0.35 ; \mathrm{z}=33.81, \mathrm{p}<<0.001$ ). For the second question (why teams tend to experience team flow), there were three raters, 235 responses, and $\kappa=0.21(95 \% \mathrm{CI}$ $0.19-0.23 ; \mathrm{z}=20.46, \mathrm{p}<<0.001)$. For the third question, there were three raters, 160 responses, and $\kappa=0.33(95 \%$ CI $0.30-0.35 ; \mathrm{z}=25.95, \mathrm{p}<<0.001)$.

\subsection{General Statements About Team Flow Theory}

\subsubsection{Mutual Autonomy}

One of the major findings from our interviews is that it is easier for team flow to occur when teams have the freedom to decide on their own what is important to them in the moment, but also to enlist help and support from external stakeholders when needed. For instance, teams in a healthcare organization we interviewed can call on support from a regional coach, as described in the following quotation:

Within Buurtzorg Nederland, our teams can do exactly those things what they think are important. The leaders express in their vision statement what matters to them as a healthcare provider. To support their vision, they offer additional schooling and encourage us to call on a regional coach whenever we want to. Coaching is all a regional coach does. They don't tell you what to do, but they do suggest options. You might try such and such, or maybe consider this, or I know of teams who handled it like this. (Employee quote 4, Buurtzorg Nederland) 
By making clear to employees that the role of overseers is solely to provide support and advice when needed, the company is giving employees the autonomy not only to decide what to do, but when to ask for help, how to ask for help, and how to capitalize on the information provided. A further implication is that the teams retain responsibility for their team members' decisions and that everyone is held mutually accountable. As such, the teams in this healthcare organization are considered selfmanaging, which is exactly what enables them to have more team flow experiences.

Elsewhere in the interviews are further indications that autonomy is essential for achieving team flow. Jos de Blok, founder of Buurtzorg Nederland, describes the principle like this: "There's a lot of stuff you see in other organizations that you really don't even need to talk about. You can just work very instrumentally, and all the stuff we don't bother with is developing policy, policy strategies, mission statements, you name it. What we do is: there's a problem to be solved, so you collect some good people with abilities that can contribute meaningfully to a solution, and you get on with it." (Jos de Blok, founder and CEO of Buurtzorg Nederland).

What De Blok advises here is to give teams the freedom to deal with problems as they see fit without trying too hard to manage or control them. He sees management and control systems as distractions that can take away opportunities for employees/ teams to apply their skills and use their best judgment. This also integrates the role of autonomy with the process of team creation-there is no reason to put someone on a team unless they have the autonomy to decide how best to do their work both independently and in the context of the team (cf. Katzenbach \& Smith, 1993). It is important to recognize that the members of professional teams are perfectly capable of identifying the right moves and determining for themselves what they will work on together. Trying to regulate the teams with policies and procedures can serve only to undermine and inhibit their productivity.

This idea is further supported by the following statement: "Team flow is about a number of individuals who can authentically be themselves in the team" (Frank Heckman, organizational researcher, lecturer and coach in the performing arts; personal communication, 2009) The more team members have the freedom to be themselves while serving on the team, the easier it is for the team to achieve team flow. This personal authenticity allows them to act on their intrinsic motivations, bring forth their top skills, and be recognized and appreciated for who they are and what they can do. This interplay of bringing the authentic self and recognizing the positive attributes that others choose to bring allows the team to construct a collective ambition that is a deliberately-constructed synergy of the skills and motivations that each member chooses to contribute.

"Professionals focus better when they know why they're doing something. For a professional what is never the issue because that's what they've been trained for. [...] The real question is why." (Expert quote 51, Harry Starren, organizational consultant and former CEO) The 'why' question is answered by agreeing on or determining a collective ambition, possibly paired with a team-level outcome agreement (e.g., common goal). As such, it becomes important for employers to communicate to their teams what they need to accomplish and why, then let the team do what they are good at to make it happen. Here we 
see that, when it comes to achieving focus, autonomy in working towards the agreed-upon personal goals is a recurring theme-decide on the "why," and leave it to the individuals to determine the "what."

\subsubsection{Small Team Size}

We also found that teams in the field should not be too large, as it can be hard it can be to blend so many authentic personalities, not to mention the potential for cognitive overload when trying to monitor the tasks of teammates and keeping the coordination in mind (see below). A healthcare organization we sampled for data reported to us that teams should be no larger than 12 people. They claim that is a hard cap, since cooperation starts to become challenging in teams with as few as 9 people (Employee quote 3, Buurtzorg Nederland; cf. Amason \& Sapienza, 1997; Haleblian \& Finkelstein, 1993; Katzenbach \& Smith, 1992).

\subsubsection{Reflection and Coordination as a Source of Focus}

The desire to experience individual flow has potential downsides. It is possible to lose a sense of how one's actions are fitting into a broader context and/or affecting the people who are not immediately involved in the activity at hand. In turn, this can cause people to overinvest in an activity, exhaust themselves, suffer tunnel vision, take excessive risks, or create social conflicts. Though empirical studies into the downsides of flow are scarce (Csikszentmihalyi, 1990; Sato, 1988; Schüler, 2012), it is safe to say that there is probably an optimal way to experience flow, in which subjects retain awareness of and can reflect on their surroundings and the needs of their peers. Flow is, after all, a fleeting experience (cf. Hetland et al., 2018), and when finished one must return to a wider world that may have been impacted by the activity and the actions of the person in flow and, if the activity continues, renovate/ reconstruct the flow experience in response. In a team, it is critical for every member to have awareness of the context to which they contribute, and thus coordination is essential for ensuring that everyone is moving in the same direction along the same path using the right skills and tools. This is reflected in the wisdom that came from an interview with one of the team experts: "For flow in teams, there probably exists some optimum of flow. Too much of it is bad because the team starts going to extremes, losing control. Too little flow leaves them nowhere. The optimum is where all the advantages are." (Expert quote 1, Ad de Jong, organizational scholar). Similarly, another expert neatly summarizes the interplay of reflection, coordination, and focus: “Team members need to know who's responsible for what, how to stay in touch with each other, when feedback can be exchanged and how to get help and support. When all of that is clear to them, team members can relax and get down to it. That gives them focus." (Expert quote 49, Ineke Khalil, business team coach). Critically, the experts highlight the fact that the need for coordination among team members provides a lens for reflecting upon individual activities and likewise for ensuring an optimal focus on the individual activities that is tempered by knowing that these efforts need to integrate with those of others. 


\subsubsection{Tipping Point}

"When my star players hit flow, the rest follows" (Expert quote 2, Marc Lammers, sports and business team coach; from a 2015 interview). That statement from a sports and business team coach suggests two things: first, that the experience of team flow is born from individual flow experiences, which is consistent with our definition of team flow, and second, that once a certain number of team members achieve flow, a tipping point is reached that pulls the rest along for the ride and brings about team flow (albeit non-linearly; cf. Ceja \& Navarro, 2011). As noted, in team flow the team members experience flow individually as well as collectively. This notion of building to a critical threshold (cf. Culbertson et al., 2015), of individuals starting to cooperate and coordinate and coalescing into a cohesive unit, appears to be a unifying thread through the concepts that were discussed both by employees and by team experts.

\subsubsection{Increased Happiness as Outcome}

Often the joint experience of happiness during a team flow experience occurs when everything appears to run extremely smoothly. Actions in the team each follow naturally from what came before, as there is a high-order alignment between: (a) individuals performing tasks at which they are skilled; (b) individuals coordinating their efforts with others in real time; (c) individuals acting to achieve goals that fit their personal values; (d) sub-teams performing coordinated tasks at which their skills complement each other to create a Gestalt-level skill to execute upon the task; (e) sub-teams coordinating their efforts with others in real time; (f) the team and subteams acting to achieve the audacious goal that the team adopted as its core nucleus. In describing the happiness experienced in the team flow that occurs when acting within this alignment, one teacher said, "We became a well-oiled machine. We cooperated, and the students had an amazing afternoon and worked on their learning objectives as well. That made me really happy for a while there" (Employee quote 5, AMO).

\subsubsection{Effortless Cooperation}

One characteristic of individual flow could be described as effortless action (Csikszentmihalyi, 1997). "Concentration and talent may well be different words that mean the same thing. Talent is the ability to concentrate. You do that because you believe that what you're doing is meaningful, so when you lose yourself in something, that's when you're really here" (Expert quote 43, Harry Starren, organizational consultant and former CEO). This point has a layer of subtlety in that having talent can make it easy to identify what to focus on and how to focus effectively in order to perform well. Past work on flow has found a similar effect when challenge and skill are optimally balanced to promote engagement (Abuhamdeh \& Csikszentmihalyi, 2009; Csikszentmihalyi, 1990). Similarly, autotelicity also has a role in the effortlessness of action, in that those who find a task important and enjoy performing it tend to experience little resistance and find 
the whole process effortless (Csikszentmihalyi, 1990, 1997). As such, deploying talent in support of a goal that one values can be effortless, and doing so in a team of people all striving for a common goal in a moment of team flow can promote effortless cooperation. Of course, the trick is still finding the right balance between coordination and autonomy. An excess of coordination will cause frustration, meaning more effort is required, whereas an excess of autonomy may cause individuals to lose sight of the common goal in pursuit of their own, leading to chaos.

And yet, autonomy is very important for professional teams to be able to reach team flow. As noted above, too much top-down meddling is a distraction that inhibits team flow. All that is needed from upper echelons is a clear overarching vision with a clear framework, protection from distracting elements, and ample support as needed. From there, the focus needs to be on professional autonomy, since that will allow team members the freedom to perform at their best and thus achieve flow in the performance of their tasks. Again, whether the right balance is struck between autonomy and coordination determines whether team members will enter flow together. Finding that balance is up to the team, and becomes more difficult as the team grows in size. If just a few people in key positions within the team enter flow while performing their tasks, there is a good chance they'll pull the rest along with them, and once the whole team is in flow together, team flow occurs. That is when the team members perform at their best together and experience happiness together.

\subsection{Collective Ambition as the Bedrock of Team Formation}

\subsubsection{The Keys to Forming a Collective Ambition: Openness, Generosity, and Meaning}

We described the collective ambition of a team as the starting point of its formation and defined it as "the shared sense of intrinsic motivation to operate and to perform as a team based on shared values and recognition of complementary skills" (see above). Embedded in that definition is the notion that each team member should recognize and value the abilities of each other member, which is tantamount to granting them a place on the team and giving them permission to work together towards a common, meaningful goal. This collective ambition is beautifully described in the following quotation:

Leave your collective ambition open to some interpretation. Formulate the ambitions generously, so that team members can imbue it with meaning of their own. When I say open to interpretation, I mean leave some wiggle room, but make sure it provides enough guidance to keep people on board without excluding anyone from the process. They should also set ambitious goals with a social aspect. People are happier when they can be of value to others, contribute to something beautiful, something greater than themselves. (Expert quote 10, Harry Starren, organizational consultant and former CEO; italics added) 
As above, it is notable that the interviewee emphasizes not only the imputation of meaning upon the collective ambition, but in the autonomy of each team member to align this meaning with personal goals so that they can apply their unique skillset to something larger than themselves.

Another quotation along the same lines says that high-performing teams are usually founded on shared values (Expert quote 11, Christian Dahmen, organizational consultant). This means members of organizations are not grouped together solely on the basis of their knowledge or skills, but on their collective values, which form the basis for collective ambition. With autonomy and team values established, the team is in a prime position to develop the collective ambition through open communication into a concrete goal, as illustrated beautifully by TV producer Victor Mids:

We handle things very professionally at MINDF*CK. When we're creating a new season, we'll rent a villa for a week. A team of five of us will sit by the pool and brainstorm. Everyone's free to say what new illusion they might find interesting. 'Shall we change water into wine,' someone will say, 'Or make the moon disappear?' We generate a whole bunch of ideas that way. After that we'll look for methods. Will we use a helicopter and a black screen? Do we build a complete replica? Do we hypnotize someone? From there, we look at what the best solution would be and whether we can make anything cool happen. It starts with a core idea. Something you can explain in just one sentence. If you can't do that, the idea's just not good enough." (Expert quote 12, Victor Middelkoop, illusionist and TV producer)

As demonstrated the collective ambition gets developed by allowing each of the team members to highlight the foci they value and to build on the aspects of those foci that they can work on synergistically. With freewheeling, open discussion, the team can drill down to a specific set of deliverables and outline an action plan, both of which serve as a source of motivation for the team.

\subsubsection{Collective Ambition as a Source of Satisfaction and Positive Energy}

It is also worth mentioning that talking about the collective ambition engenders feelings of satisfaction, as reflected in the following quotation from a team member in education: "The first time we all sat together, we had some intense discussions and decided what was important to us. That felt pretty good" (Employee quote 6, Bossche Vakschool). As in this case, we saw across the interviews (e.g., Employee quotes $22,32,36)$ that team members' being surrounded by highly motivated people led to flow experiences for them as well. The collective ambition becomes a touchstone for the team-by revisiting it frequently, the team members, both individually and collectively, can use it as a source of energy, reflection, and alignment, which keeps positive momentum flowing in the right direction (double entendre intended).

Moreover, knowing what you stand for as a team and what is important to the team can be viewed as an actual strength of the team, as indicated by this member of a team in education: "One of our team's strengths is that the team knows what all of its members stand for, together" (Employee quote 11, Dimence). This sentiment is echoed by a healthcare team member: 
It's so important what the vision of one of these organizations is. I never knew just how important that is. Buurtzorg organises vision meetings for new employees to teach them about its vision. And it's a vision we all support. In fact, their vision should be the entire reason you choose to work for Buurtzorg. We ask about it in job interviews. "Why do you want to work for Buurtzorg and what do you think makes us different?" If the answer to that question gives us a bad feeling, we won't continue with that applicant. (Employee quote 14, Buurtzorg Nederland)

That also suggests how important it is that the team's values match the organization's. The team's collective ambition should contribute to the overarching mission/vision of the organization as a whole. If at any time the two fall out of sync, that will form an obstacle to team flow for any number of reasons, including a lack of cooperation, a refusal to share resources, and others.

\subsubsection{Balance of Collective Challenge and Complementary Skills}

Challenges are tackled together, at the team level. That means there ought to be a balance (or match) between the collective-level challenge and the levels of the team members' complementary skills. To achieve a high level of skill integration, the division of labor should be performed in such a way that everyone is assigned a task or role they will find challenging and that matches their preferences, talents, knowledge, and skills (see our point about autonomy, above). A crucial part of this process is assigning people to tasks that fall within their respective zones of proximal development (cf. Obukhova \& Korepanova, 2009), as one of the expert interviewees noted: "In role distribution, consider everyone's talent and motivation to develop in any given area" (Expert quote 49, Ineke Khalil, business team coach). By using that framework, individual abilities are optimally directed and prone to being bundled in ways that generate both personal growth and cooperative synergies. This also increases the likelihood of everyone's functioning at proportionally high levels of ability, uniquely contributing to the team's meaningful goal in a way that is simultaneously autotelic to the individual. This also makes it easier to delegate tasks and coordinate efforts, both because the individuals are motivated and because they are likely to communicate the ways in which they want to contribute to the coordinated efforts. We found this effect reflected in multiple statements across the interviews:

"One of our team's strengths is that you know about each other what your strengths are" (Employee quote 30, Dimence).

("A clear distribution of roles and responsibilities where everyone complements everyone else by bundling strengths" (Employee quote 38, Mammoet). "I get into this flow because my team and I are given full responsibility. Everyone on the team is well-trained and knows what they're about. We're free to divvy up the work. Everyone does what they're good at, what they enjoy doing, so of course things go really well. And you get to be completely responsible for that, too" (Employee quote 36, Buurtzorg Nederland) 
Though it is sufficient for the collective ambition of a specific team to be operationalized in a way that leaves room to maneuver, the best collective ambitions encourage teams to strive for something beautiful, meaningful, and socially relevant (a higher purpose, added value, or core belief). The collective ambition, then, reveals more of the common values that the team stands for. The personal goals that have been decided on are all carefully formulated, meaningful, and specific to the individual, directing the individual's actions and encouraging growth and development in both the individual and the team as a whole (Locke \& Latham, 2006). This higher level collective ambition serves to inspire team members to improve both themselves and the team as a whole, which reflects high motivation and effortless cooperation. When everyone on the team agrees fully on what the collective ambition is and everyone in the team has the autonomy to strive for that ambition as they think best, everyone involved will be highly motivated. As such, the formation of an effective team truly starts at the mutual recognition of each other's overlapping and complementary values, and the common strength derived from those (cf. group potency; Guzzo et al., 1993). Building on this unifying team self-efficacy, the team's collective ambition serves as its beating heart, energizing its members, as well as its backbone, ensuring that all the team's efforts are coordinated. Because of the coherence, efficiency, and efficacy that follow from strategic team composition and development of a collective ambition, the collective ambition is the root from which all other team flow prerequisites develop.

\subsection{Interconnected Elements of Team Flow}

\subsubsection{Common Goal and Aligned Personal Goals Drive a Sense of Unity}

A common goal is integral to instilling a sense of unity in the team. Respondents repeated this point constantly, and it is visible throughout the quotes in Appendix 1. Some examples are: "The idea is for us all to get behind the goal" (Employee quote 19, Dimence)."; "Linking clear goals to ideals and living up to those" (Employee quote 21 , M\&O Groep); "Getting on with it together and making sure everyone's on the same page" (Employee quote 63, De Bossche Vakschool).it is important for goals to be clear and supported by everyone involved, as this maximizes the chances for achieving team flow. Once a common goal has been agreed upon, team flow may be further encouraged by enabling each team member to develop a concrete plan for making a unique contribution (e.g., drafting a clear task flow with deadlines, integrating with other team members' efforts). The aim is to give the team (including individual and collective subunits) the wherewithal to draw the team's focus (collectively and/or individually) into the here and now without anyone losing sight of the long-term collective ambition and the goals derived from it.

The difference between a collective ambition and a long-term common goal is that the latter is much more concrete, like taking the cup at the World Championships, whereas the former is more like wanting to be the best football offensive side in the world by playing beautifully and with great technical proficiency. Our respondents describe the importance of this multi-level clarity as follows: "Clear 
goals and their associated tasks give me the feeling that I'm valuable to the team and allow me to fill my day with meaningful activity" (Employee quote 24, Zaanstad); "People want to express their passion by doing their jobs well. They want to take enjoyment from their work, and do it in a way that makes them feel like they're doing something meaningful. Personal goals in the team are a part of that" (Expert quote 20, Jos de Blok, CEO Buurtzorg Nederland)."; As such, the individual brings their whole self to the team, which can mean that there will be egos in the group. This is fine, as long as the egos are able to blend and/or be put in the service of the team's interests (cf. blending of egos; Sawyer, 2007). One of the team member respondents described that phenomenon in an interview:

If you want to work at Buurtzorg, you can't have a large ego. Many other organizations demand one. At those places, one person usually steps forward wanting to be the manager. Here, everyone needs to carry themselves as equals. That creates trust, opens up communication, and eventually leads to flow in your team. (Employee quote 1, Buurtzorg Nederland).

Having a collective ambition, a common goal, and personal goals aligned to them both creates a sense of unity in everyone involved. Team members experience this in a very real way, as if they are acting as a single organism. Here is one example quotation from the interviews illustrating a sense of unity: "One of our team's strengths is that there's a strong sense of "togetherness" (Employee quote 73, Dimence). In summary, we can say that the chance of experiencing team flow improves when team members get to make personal contributions to the common goal, and that it can be even further improved when that contribution stimulates personal development. Under those conditions, the aligned personal goals together stimulate the sense of belonging and of being valuable to the people they serve. Clearly, the prerequisites common goal and aligned personal goals and the characteristic sense of unity are strongly interconnected.

\subsubsection{The Alignment of Personal Goals Should Be Interwoven with the Integration of High Skills}

As discussed above, clear goals and aligned personal goals provides a foundation for open communication about task delegation, starting with developing an understanding of who is good at what and who enjoys doing what (mutual awareness), as well as what the team as a whole is good at (collective awareness). With those elements in place, team members engage in tasks on the basis of their talents and stay connected through the coordination of people's unique contributions (mutual autonomy). Because everyone has some autonomy and feels free to get on with it, it becomes easier for everyone to experience flow in their performance of personal tasks supporting the team (cf. autotelic activity; Nakamura \& Csikszentmihalyi, 2009). This is reflected well in the following statement:

If people assign me a role I'm happy to fill here [sic]. I can exercise my authentic qualities in a focused way here. The group knows what those qualities are and lets me make the most of them. I can stay true to my 
authentic self here in the way I interact with clients. I can be myself here in the way we work with clients. (Employee quote 28, Dimence)

By allowing team members to be themselves while also giving them a shared responsibility, they have a greater likelihood of experiencing team flow. This is summarized wonderfully in the following quotation:

I've been at this for a while now, and when I joined Buurtzorg and read on the company intranet that someone's experience of working there was: 'This is so great,' I felt the same way. This is something else! This is a whole new approach to working and to teams. You can just be yourself. And they make the most of my skills and responsibilities, which makes me derive so much more joy from my work. I'm well aware how I hit flow at Buurtzorg. A lot would have to happen before I lose that ability. I get into this flow because my team and I are given full responsibility. Everyone on the team is well-trained and knows what they're about. We're free to divvy up the work. Everyone does what they're good at, what they enjoy doing, so of course things go really well. And you get to be completely responsible for that, too. (Employee quote 36, Buurtzorg Nederland)

\subsubsection{High Skill Integration and Open Communication Provide a Sense of Joint Progress}

In this, it becomes clear that high skill integration couples with the mutual commitment of both team and personal goals to promote team flow, in large part due to a sense of joint progress. When the disparate skills of team members are integrated into a collective skill set and when there is constant coaching towards the next step along the path towards achieving the team's collective ambition and/or common goal, that creates a feeling of joint progress (cf. moving forward; Sawyer, 2007). That feeling leads to the sense of effortlessness that is so strongly associated with individual flow (cf. effortless action; Csikszentmihalyi, 1990), only in the team context the experience is shared with the team. One respondent described how that happens: "When allocating tasks, you need to bear in mind what people enjoy doing. If you don't, people start grumbling, feeling negative. That creates a negative atmosphere in the team. The thing to do is tell people to do the things they like to do and are good at. They'll make it look effortless!" (Employee quote 34, Buurtzorg Nederland). When people get things done together with what seems like very little effort, they get more done overall, as two respondents noted: "I experience flow in this team when I get absorbed in the work, have the chance to really put some effort in, and get a lot done" (Employee quote 85, AMO); The team plays a crucial role. The team has to function well for me, as an employee, to be able to function well" (Employee quote 84, Dimence). When the entire team functions well, the team experiences the sense of joint progress aspect of team flow. 


\subsubsection{High Skill Integration, Mutual Commitment, and Open Communication as Foundations for Safety}

Creating a safe environment that is tolerant of failure is essential, as only those who can commit fully to attacking challenges without fearing failure are in a position to experience flow (Csikszentmihalyi, 1990; cf. Sawyer, 2007). Safety creates mutual trust and allows people to make themselves vulnerable:

If there is ever a problem with a client, your colleagues are always right there for you. We start looking for solutions together. We help each other. That's a thing: you can ask for help here. You can make yourself vulnerable in the team. That's how much trust we have in each other, and that trust is never violated. (Employee quote 59, Buurtzorg Nederland)

That quotation indicates that the willingness to ask for help, to appeal to the team for support on one's weak spots, and for them to give what they can and to do what they can (i.e., integration of high skills) is dependent on the sense of safety.

The team members support each other in working towards the challenging common goals they set, embracing failure as a source of growth and learning and acknowledging success through accountability and celebration. These open, constructive, and positive exchanges are considered essential for the creation of a shared safe environment. There were numerous quotations about safety and the prerequisites for team flow: "Our team's strength is that I can just tell my colleagues how I'm doing. The team knows how I feel on any given work day" (Employee quote 44, Dimence); "An important measure of the support our team receives is that difficult situations are acknowledged within the team as well as by other teams, other departments and the management" (Employee quote 45, Dimence); "A common project on which everyone contributes within the deadline and there's open communication about progress" (Employee quote 49, Mammoet)." Creating a safe space where the need for recognition and appreciation as well as feelings of disappointment can be acknowledged plays an important role in the process. Expressing mutual appreciation and celebrating successes together increases motivation and makes for a positive work environment (cf. Hackman \& Wageman, 2005). The ability to manage, express, perceive and interpret emotions makes for more effective communication and is essential for the creation of a safe work environment (cf. Edmondson, 1999). There is a reciprocal interplay between open/effective communication, vulnerability, and safety, in that each of them promotes the others and joins with them to yield mutual trust.

\subsubsection{Safety and Open, Positive, Constructive Communication Supports Mutual Trust}

People need to feel safe to be vulnerable, express their feelings, and make mistakes, and from there they can develop a sense of confidence that they can get the job done together. A safe environment with open, constructive communication contributes to that trust. Trust, once achieved, reinforces all the other elements that make a team effective: "Trust affects the entire team process. If there's no trust, friction will run 
rampant. Team members will lose focus, communication and harmony (Expert quote 35, Ineke Khalil, 2013).” This expert also pointed out that:

You can restore trust by investing in it, which you do by communicating openly with each other, ensuring that roles are clearly defined and assigned. Keep talking to each other about the work you're doing. Take what time you need for that, and for acknowledging people's accomplishments. Also learn how to communicate with each other meaningfully, so that people start sharing inspiration and revealing vulnerabilities. Discussing personal ups and downs in a team contributes to building trust. Talks like that could be about someone's hobbies, their past, their family, anything. When talking about trust, bear in mind that it's not stable. Trust can be damaged at any time, so it always requires maintenance or repair. (Expert quote 39, Ineke Khalil, 2013)

Because authentic and vulnerable communication is a two-way street, and necessarily involves both personal and professional aspects, open communication is one of the keys to building mutual trust and unity. As Ineke Kalil (2013) noted (Expert quote 31): "Unity comes from trust and trust comes from keeping in touch and knowing what's going on with everyone." Similarly, a respondent said: You have to be able to trust your colleagues implicitly, trust them to provide the kind of care we stand for. It's about trust in their professional know-how, trust in their relationship with the client and their mutual trust in their fellow team members. If that's not in place, the flow isn't there" (Employee quote 77, Dimence).

But, people sometimes find themselves in teams with others they do not know and have not worked with before. It is important for the attainment of team flow that those people come to trust each other, but that can be challenging. Over time, as these people cooperate, invest in becoming better acquainted, and coordinate and succeed together, their mutual trust will grow, enhancing the team's chances of experiencing team flow. Often, the idea that teams should have open, freewheeling communication can draw people away from the fact that communication still needs to be intentional, empathetic, and accepting, which requires significant emotional management in the early stages. That is not to say that people should be thinking so much that open-communication is impeded, but rather that the communication may be a bit slower, and there may be pauses that people will need to accept. Keeping irrelevant thoughts and non-accepting emotions in check is a challenge, but very much necessary, as one expert pointed out:

Open communication requires two things: that the core of your message is clear and that you are clear on what the core of your message is. What you often see is that people will just throw stuff out there, disturbing the team's open communication. This happens because their messages hide all kinds of unexamined feelings, partially formed ideas, and confusion. It will take the other person in the conversation a lot of energy to work out what you're trying to say. People need to think: what do I really want to say. Be clear about that, then start thinking about how to put that across as palatably as you can. When someone is trying to make a statement they're very excited about, all that charge on the message can spook the audience and cause them to fire back. 
Making your message palatable means putting the core of the message across as inoffensively as possible. Open communication demands that people take a lot of care in how they express themselves and that takes a lot of self-discipline and self-awareness. (Expert quote 29, Ineke Khalil, business team coach)

That is, it is not just whether people communicate openly, but how they offer that communication in an open and accepting environment (and what they do to make the environment open and accepting) that matters. By handling this well in the early stages, the team builds mutual trust, which (as above) powers unity and holistic focus.

\subsubsection{Mutual Commitment to Common and Personal Goals Provides Focus}

Mutually committing to a common goal means becoming responsible for working towards that goal with diligence and dedication. Those involved know how the tasks have been distributed, are familiar with the process[es] that lead[s] to the goal, and stay informed about the current state of affairs. There is mutual support through task-oriented coaching and by holding each other accountable.

This was reflected in the interviews as well: "One of our team's strengths is that we all stand together when it comes to handling and being able to handle specific situations" (Employee quote 66, Dimence); "Within the team, everyone's very engaged with each other. Everyone knows how everyone else feels about things. That helps us function as a team" (Employee quote 67, Dimence). Study participants explained mutual commitment in terms of 'being there' for each other; being able to count on each other, keeping promises, going for the goal together (team spirit; cf. Employee quote 72, Mammoet), holding one another accountable for their performance and actions, making decisions together, and helping each other out when necessary. Making clear agreements, rules, and decisions together, taking a positive attitude to work, having mutual respect, and knowing each other well all contribute to the achievement of mutual commitment. When those conditions are met, it becomes much easier for the team as a whole to be in the moment. Everyone will be completely focused on the achievement of the common goal and maintaining a healthy team dynamic.

Even with a diverse team of different personalities and diverging opinions, it is important for everyone to be so invested in each other that remain willing to do the work for each other's sake. The following quote provides another good summary of the importance of commitment, common goals, and the coordination of personal contributions:

When the distribution of roles is clear and it is clear how team members stay in touch with each other. It's the interplay of owner and co-owner. I may be responsible for a given product, but my colleagues share in that responsibility because we are collectively responsible for our overall performance. Team members need to know who's responsible for what, how to stay in touch with one another, when feedback can be exchanged, and how they can ask for help and support. When all that is clear, team members can relax and go for it. It provides focus. (Expert quote 49, Ineke Khalil, business team coach) 


\section{Discussion}

To conduct these studies, we collected qualitative data through interviews and answers on open question via surveys. In addition to confirming extant research on the elements and characteristics of team flow, this study was aimed at analyzed the relationships between the constructs at the experiential level. Past research (e.g., van den Hout \& Davis, 2019) has summarized the theoretical relationships between these items, and survey data have confirmed the theories, but this differs from the rich descriptions available in qualitative studies. The results of our interviews provide confirmation of the existing research on team dynamics, flow, group and team flow (e.g., Pels et al., 2019; van den Hout et al., 2018; van den Hout \& Davis, 2019). With the collected qualitative data in this study we found evidence (indications) that team flow emerges from a collective ambition that forms the basis for all the other elements of team flow. The collective ambition shows a strong relationship with the prerequisites of open communication and common goal. Tasks are distributed based on established personal goals, all of which are aligned with the common goal. Goals provide challenges and opportunities for growth and development to which everyone collectively commits (mutual commitment). The common goal combines with mutual commitment to create a team-level holistic focus on the common goal. When it comes to task distribution, the members' personal goals (their contributions) are strongly and synergistically connected through high skill integration. Open communication about the collective ambition energizes the team and allows its members to exchange the feedback needed to excel as a collective. This positive and constructive communication enables the kind of coordination that makes optimal use of the team's high and highly integrated skills to yield results that inspire a sense of joint progress. High skill integration, mutual commitment, and open communication contribute to the creation of a safe environment (safety) and promote the mutual trust and confidence the team needs to tackle challenges together.

When all the elements of team flow are present, that signals the emergence of a team flow experience. Such experiences provide a team and its members with satisfaction, happiness, and the motivation to tackle more challenges together. It is important for the experience of team flow that organizations give their teams license to act autonomously. Autonomy is important within the team, as well; team members need to allow each other to perform their tasks autonomously. The trick is to find the right balance between maintaining alignment with the mutually agreed-upon goals and retaining each team member's professional autonomy. As noted, formulating a collective ambition is mission critical. The collective ambition could be regarded as the instrument for ensuring that team members cooperate based on shared values, acknowledging each other's skills and abilities and working together effectively and efficiently in a positive team dynamic of their own creation.

Despite following the established protocols of qualitative research, as above, this study is not without limitations. Among the primary limitations, as is often the case in qualitative studies, is the small sample size, limited duration of the study, and the mitigated diversity of the sample. By contrast, the large number 
of internet survey responses and significant number of categories relative to the lengths of the answers made categorization a challenge, and while the interrater reliability was on the lower side of acceptable, the results remained statistically significant and thus did not qualify as chance results. In addition, we note that, unlike in many qualitative studies, the reviewers achieved these results without collaboration before or after the analysis and did not argue out differences of opinion, all of which would have increased reliability. It is notable that the agreement was in an acceptable and non-chance ranges, but we do recommend that future studies allow for stronger calibration between coders.

The interviews could do with expansion to include more diverse teams (e.g., industry and/or countries) and it would also help to follow teams for a longer period of time. The latter would allow for a more systematic data collection approach that simultaneously employs both qualitative and quantitative methods in order to triangulate results (e.g., survey data with the Team Flow Monitor, systematic observations of team collaboration events, etc.; cf. Yin, 1994). This would enable monitoring of the teams' development over time in addition to having the potential to observe the development of a team flow experience in real-time with both in-the-moment and retrospective commentary. A longer period of observation would also allow researchers to monitor the teams through multiple cycles of striving for their common goals. Such data could provide additional insight into the long-term effects of becoming aware of team flow, and moreover its effects on team performance and feelings of happiness.

Likewise, a common challenge with qualitative studies is balancing the need for a grounded approach and leaving open the possibility of occurrences that are not predicted by the theory. The basis for this study was an extensive and empirically tested theory that covered a wide range of constructs within the teamwork literature. As the aim was to understand the experiential connections between those constructs, researchers in such a study need to walk the fine line between presenting the constructs to participants to ensure that their comments are cogent, but not to bias the participants by anchoring their responses in the constructs. Any method of doing this will have inherent biases, but, by using multiple types of inquiries over the course of this study, we aimed to offer different biases at different times with a view towards triangulating the results into a coherent whole if the results obtained by the different methods agree. As we did find such agreement, we consider these results an insight into the relationships between the elements and characteristics of team flow, and hope that these will serve as a basis for more extensive studies. But, there does remain an element of bias in each piece that does not fully cancel out across different methods of inquiry, and we hope that future studies will be able to use more detailed methods (such as the ones posited above) to provide clearer and more accurate views of the mechanisms that promote the emergence of team flow.

Because of the increasing importance of teamwork in handling the complex tasks that face people across all walks of life, it becomes important to know not just the elements that make up a good team, or the constructs that enable optimal team experiences and high performance, but how the pieces fit together in the experiences of the team members. As decades of teamwork research have found the elements of successful team dynamics and performance, and these are continually being refined and updated to match the times, it becomes important to fill in the experiential interstices 
that exist between these touchstones. This study has been an initial foray into understanding how team flow is experienced as it emerges, blossoming out of the collective ambition and developing into a synergistic experience of high performance that fertilizes the motivation to reconvene for the building of future team works.Hout

\section{Appendix}

Table 1 Interview questionnaire

Demographic questions

Respondent's name:

Team respondent:

Age:

Educational attainment:

Sex:

Number of years of work experience:

Permanent or temporary contract:

Respondents' instruction

We are looking for critical events in your team that will boost your mutual cooperation. Events that ensure that the collaboration runs smoothly, as if it went by itself, while still performing a challenging joint task

Questions positive critical event:

1. Name a critical event in your team that brought you as a team into optimal cooperation. Describe this event in a few lines

2. When did it take place (quarter, year)?

3. How did this event affect your work?

4. How have these activities affected your teammates?

5 . How did this event affect your service to your clients?

6. What other effects has this had?

Questions negative critical event:

1. Name a critical event in your team that got you stuck as a team and the collaboration no longer worked. Describe this event in a few lines

2. When did it take place (quarter, year)?

3. How did this event affect your work?

4. How have these activities affected your teammates?

5 . How did this event affect your service to your clients?

6. What other effects has this had?

(When there is time left)

Extra questions for determining moments of team flow

$\mathrm{X} 1$ : Do you feel that you were completely absorbed in your task for the team during the positive event described above?

$\mathrm{X} 2$ : Can you describe this feeling more closely?

X3: Do you feel that your team members were also completely absorbed in their task during this positive event?

$\mathrm{X} 4$ : What possibly allowed you to immerse yourself in your task?

X5: What possibly made your teammates completely absorbed in their task?

X6: If you were totally absorbed in your tasks for the team together, did this bring something extra? If so, what?

X7: Can you describe the feeling of being completely absorbed together in the activities for the team? 


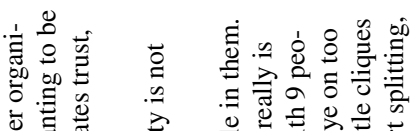

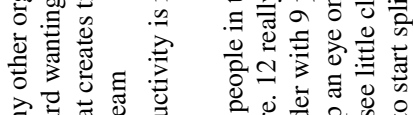

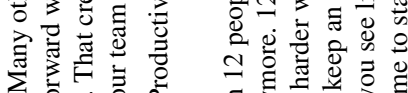

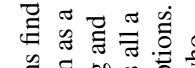

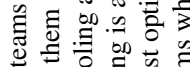

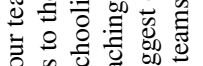

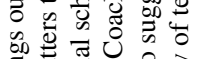

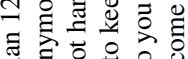

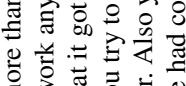

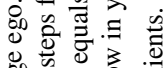

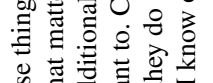

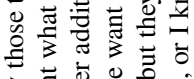

ส

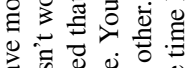

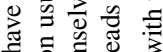

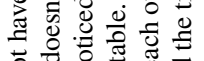

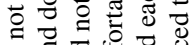

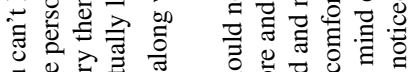

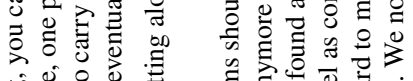

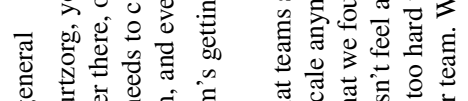

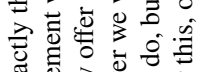

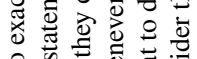

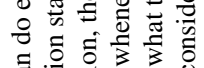

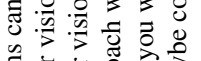

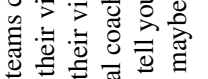

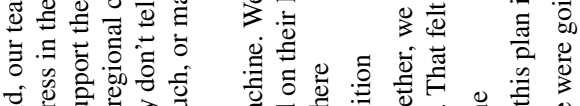

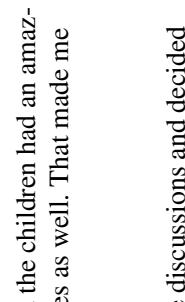

0
0
0
0
0
$\vdots$
0
0
0
0
0
0
0
0
0
0
0
0

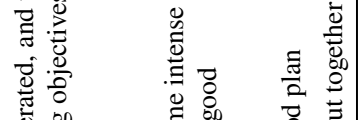

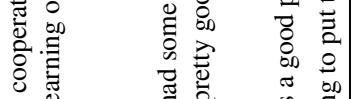

$3 \frac{0}{10}$

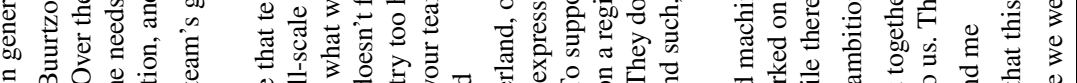

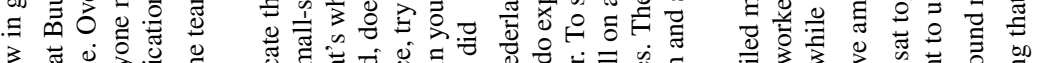

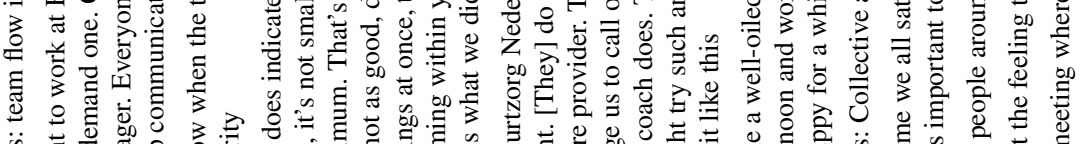

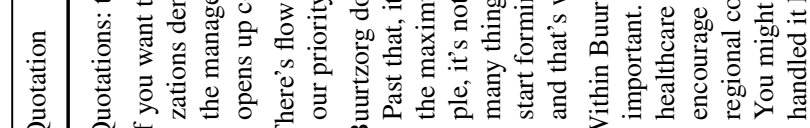

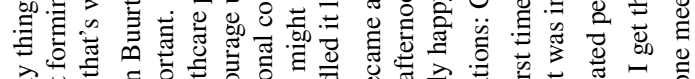

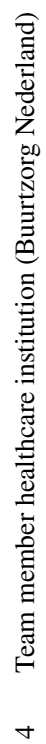

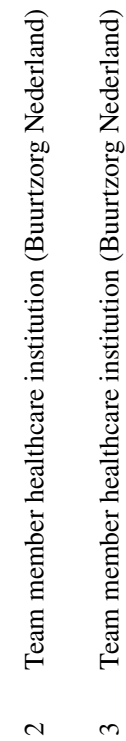

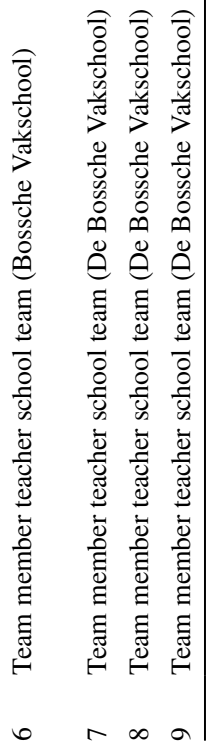




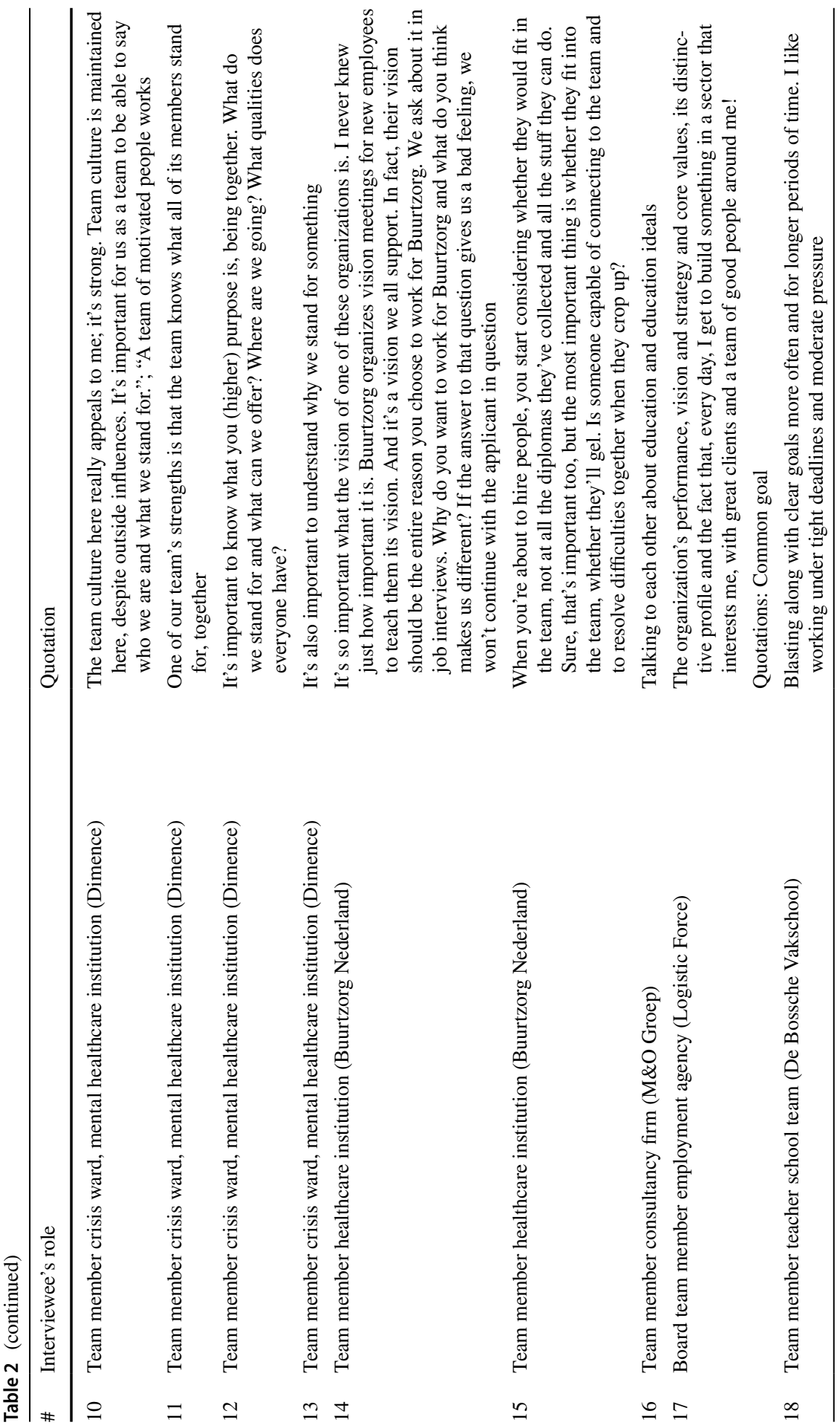




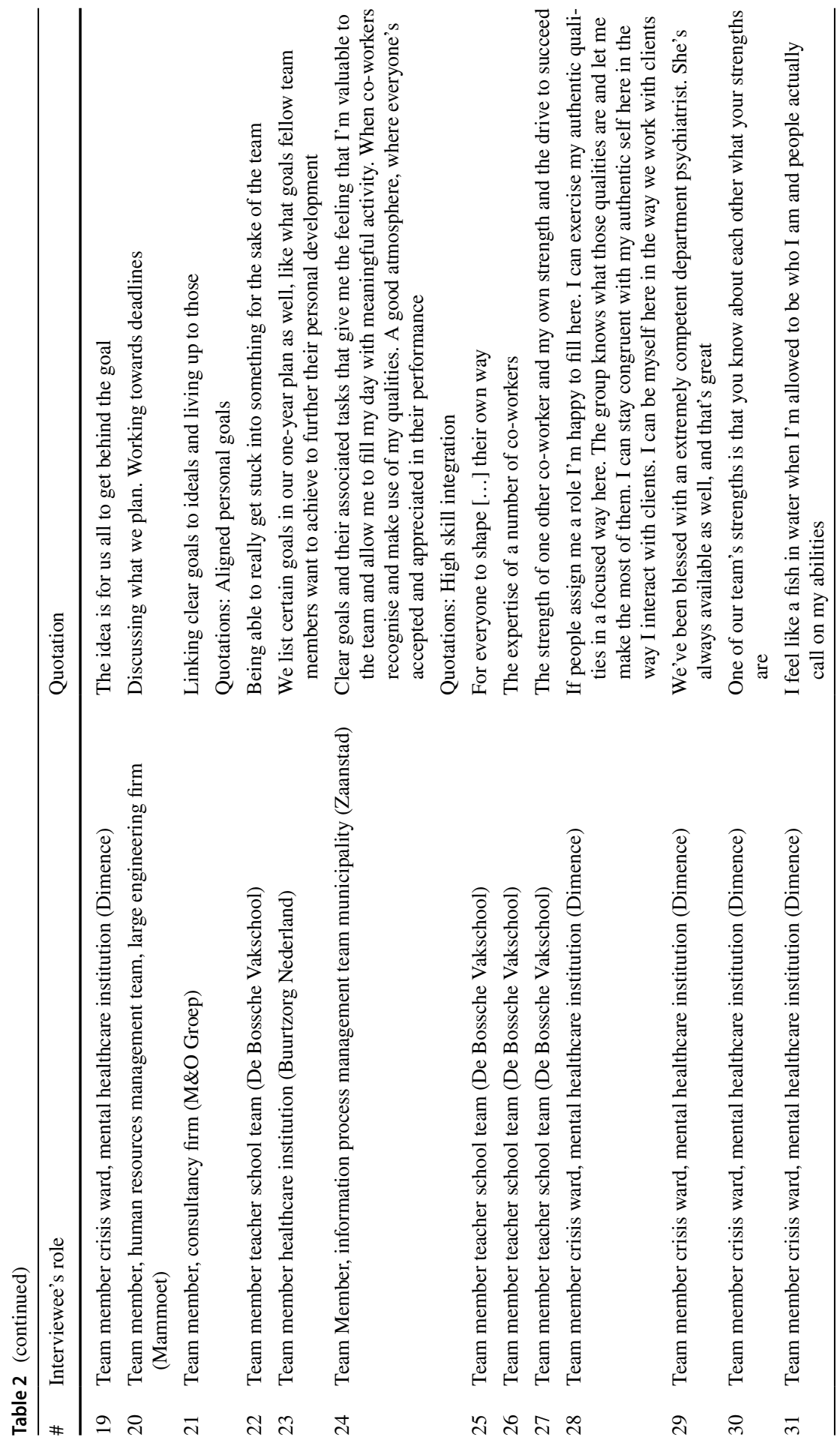




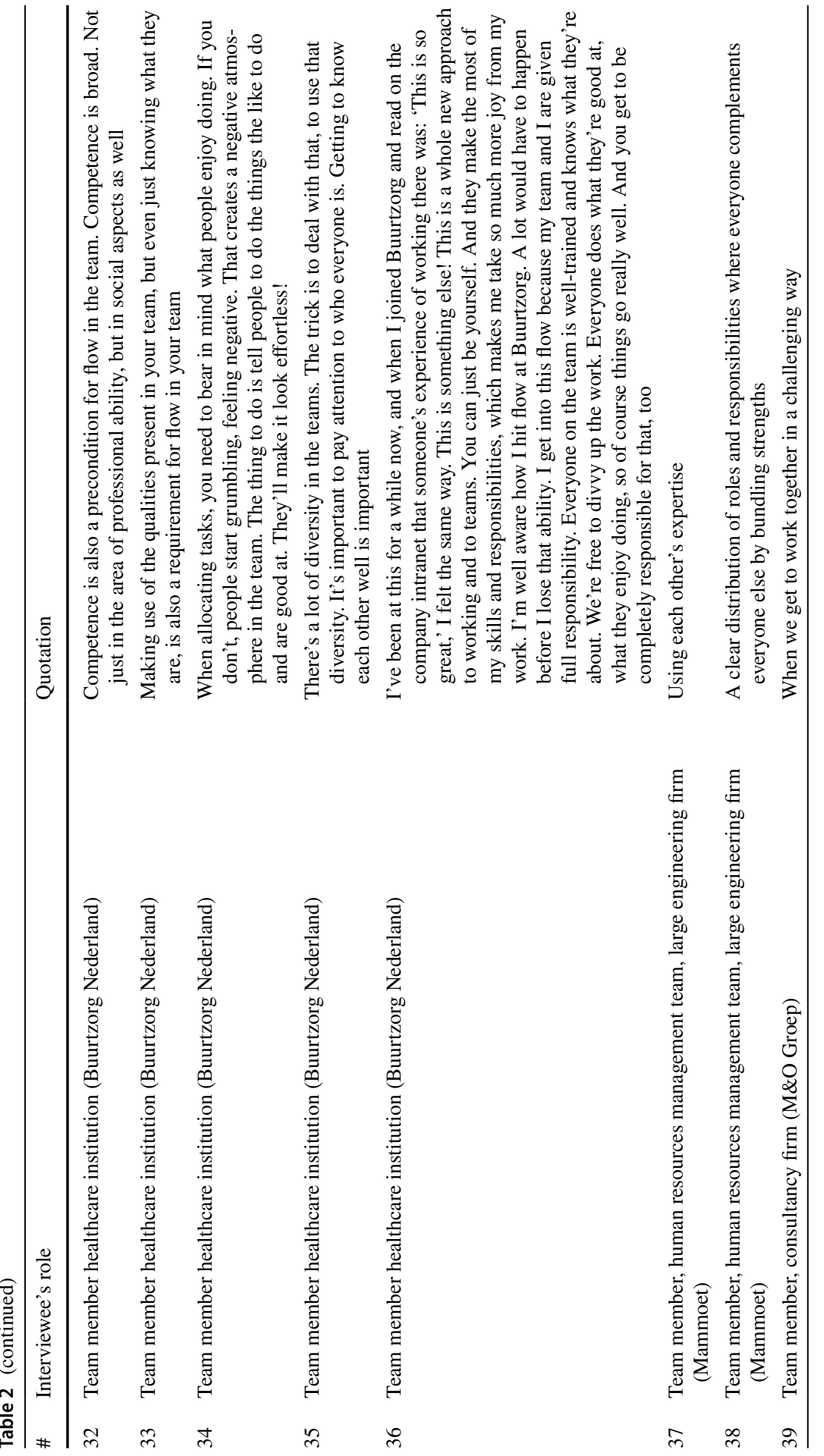




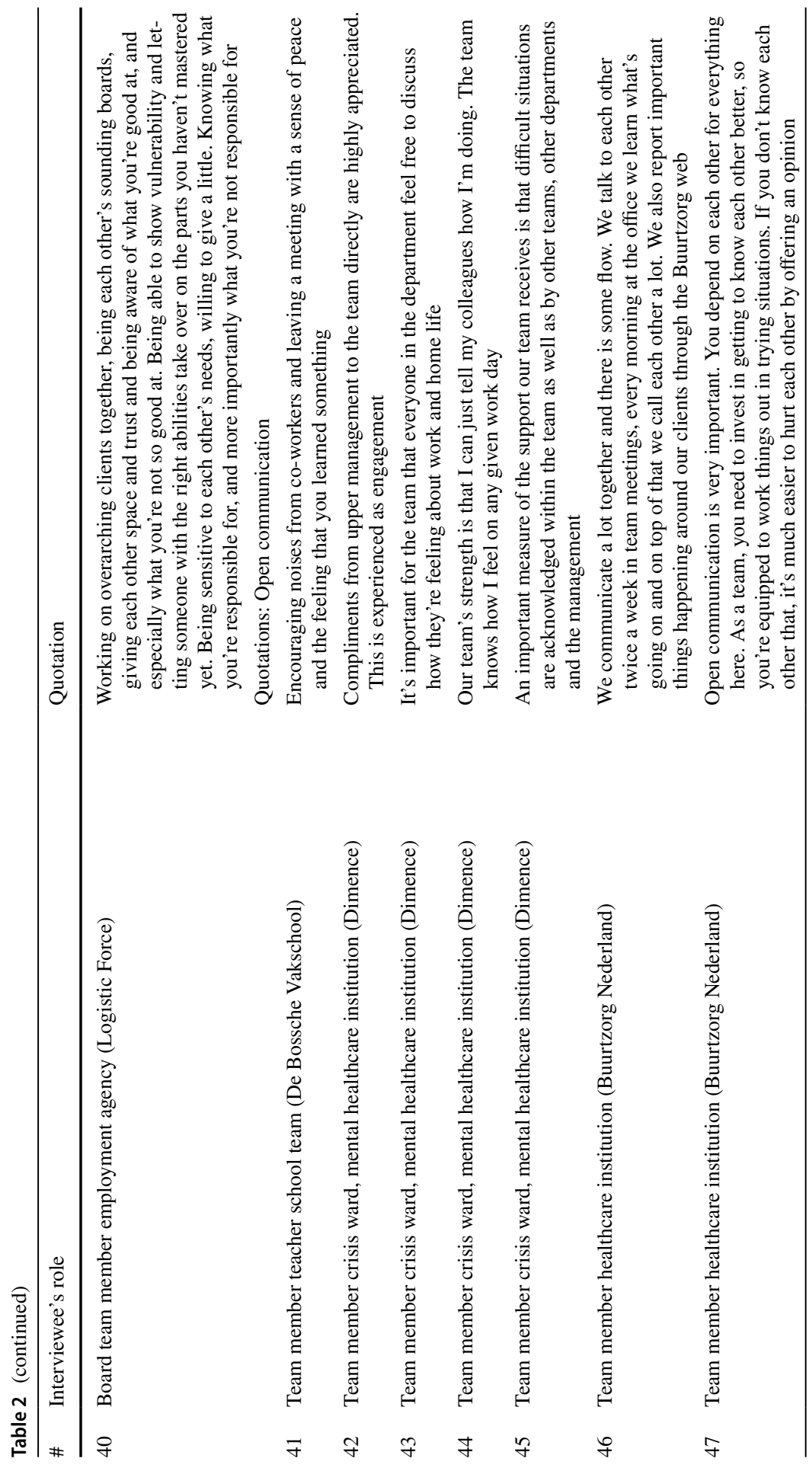




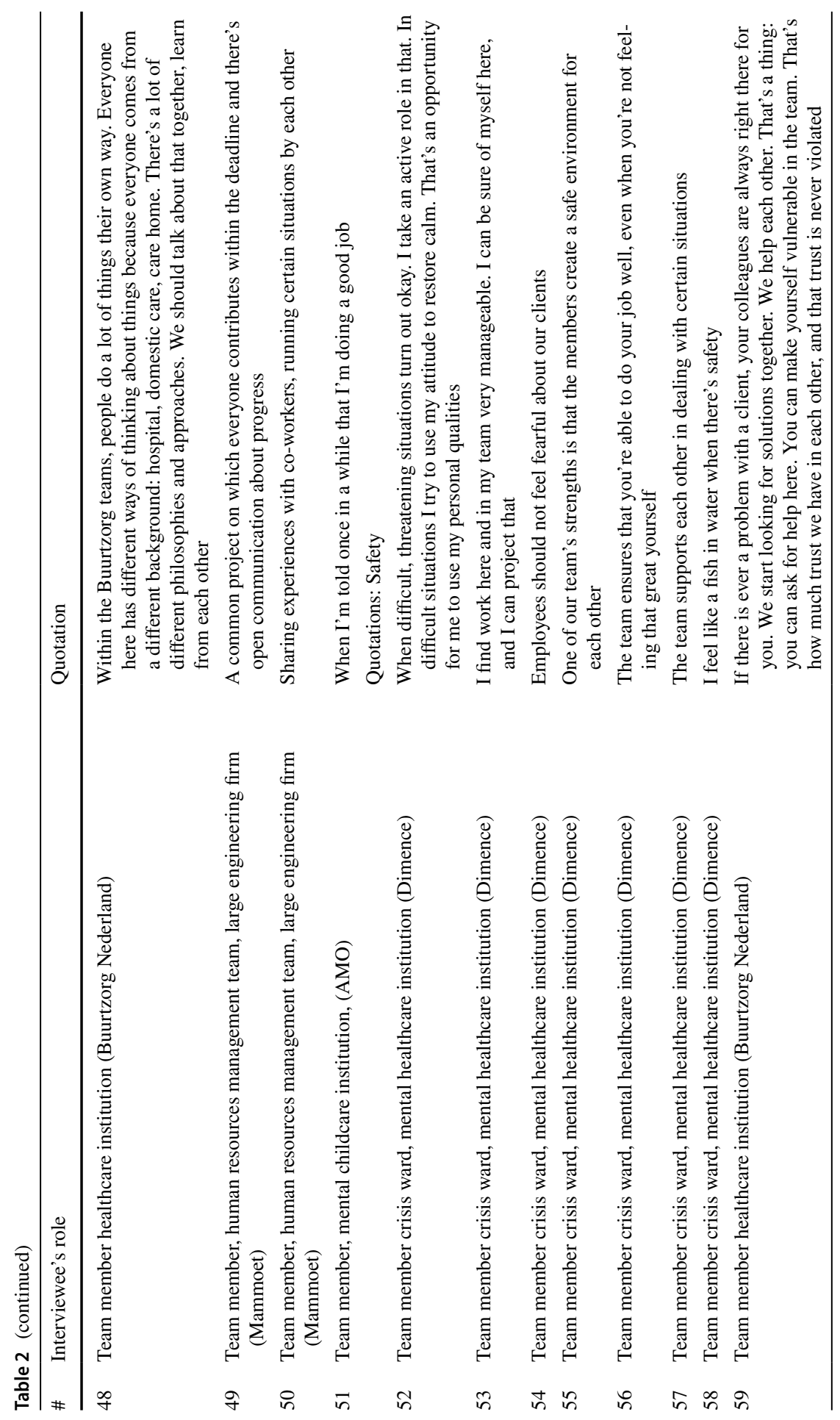




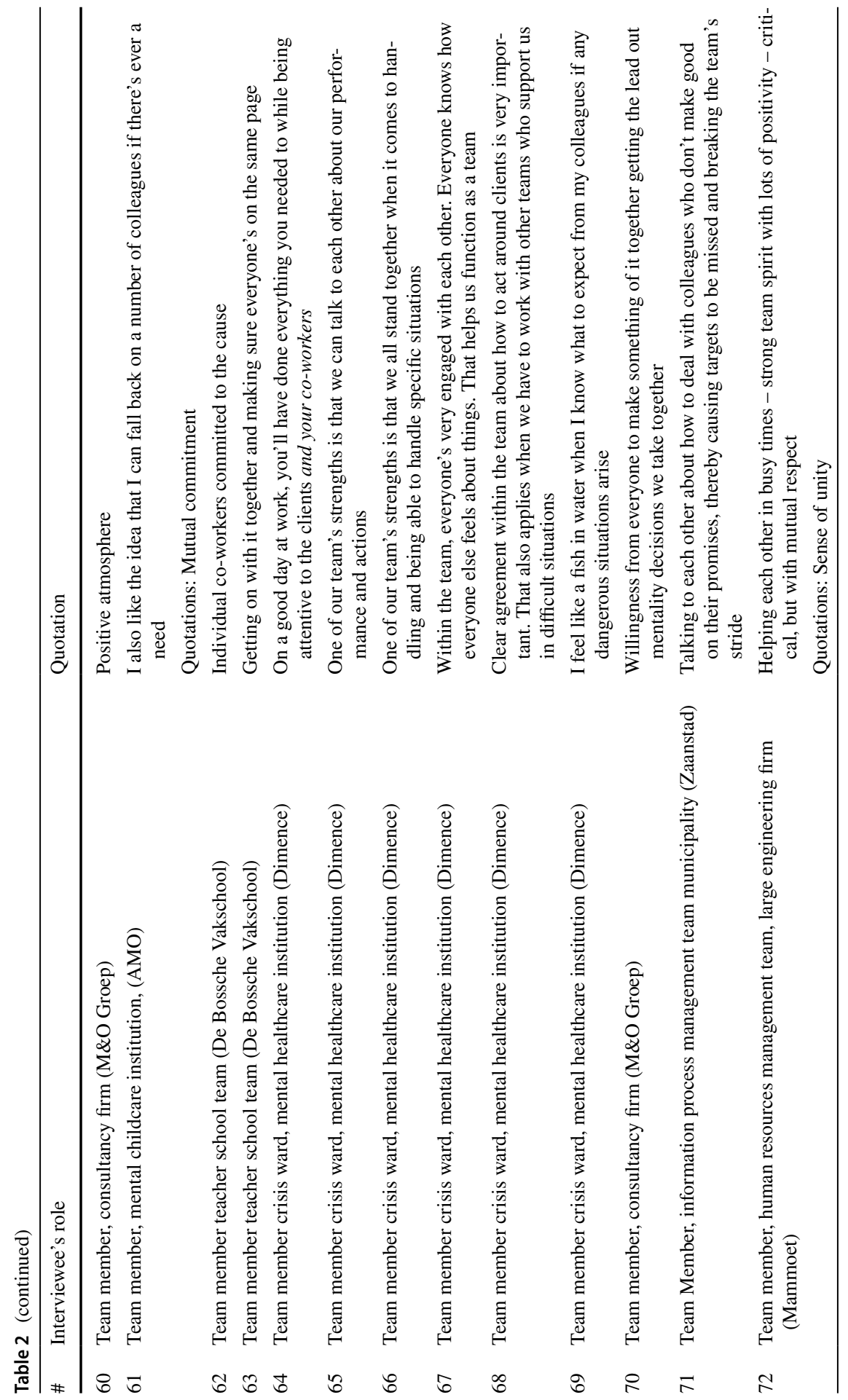




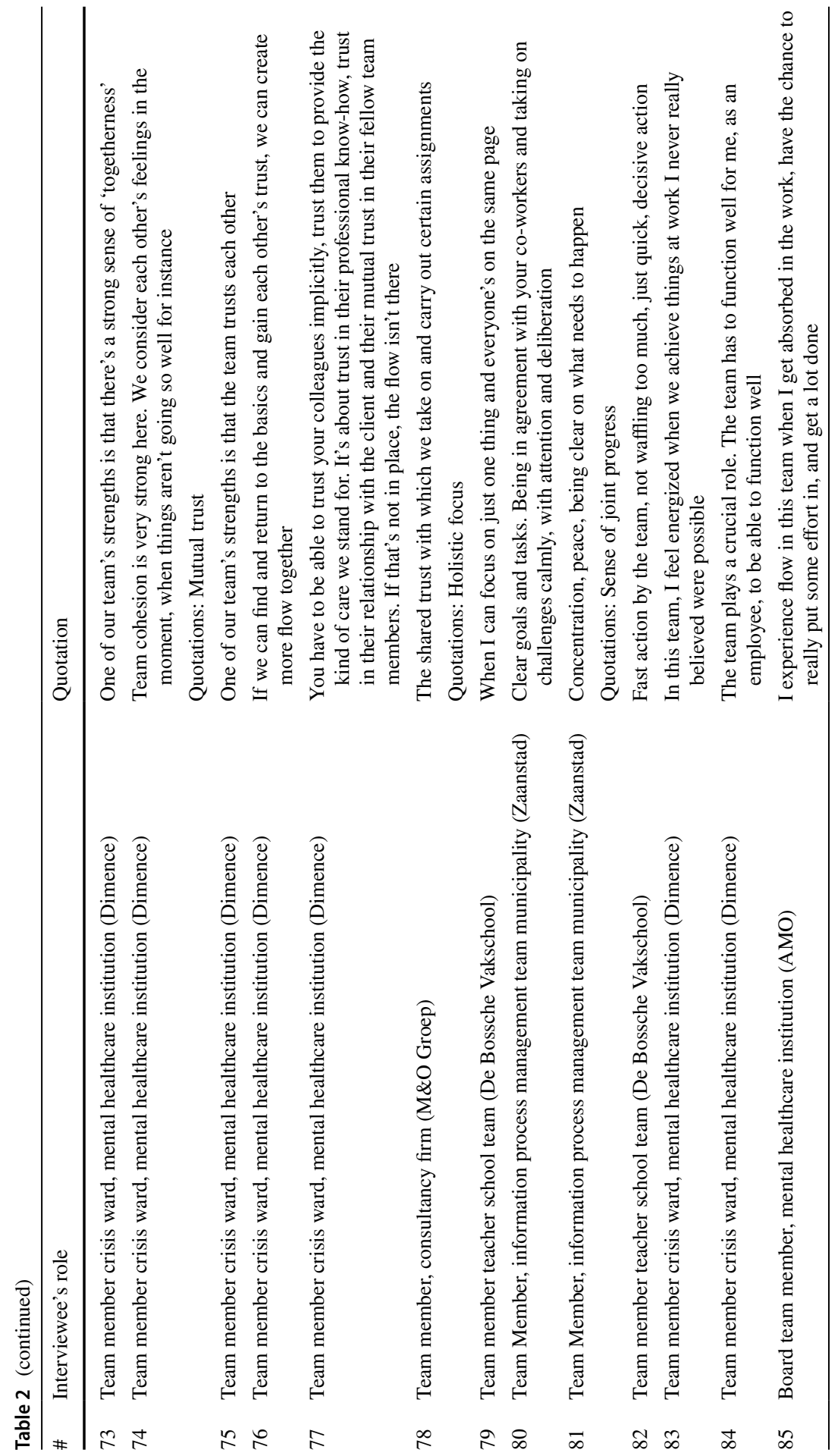




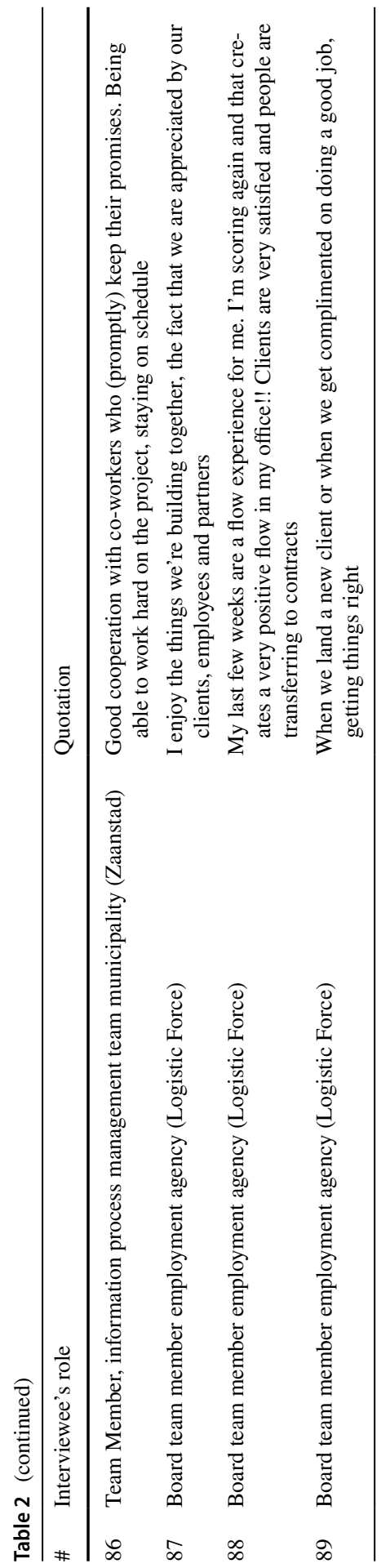




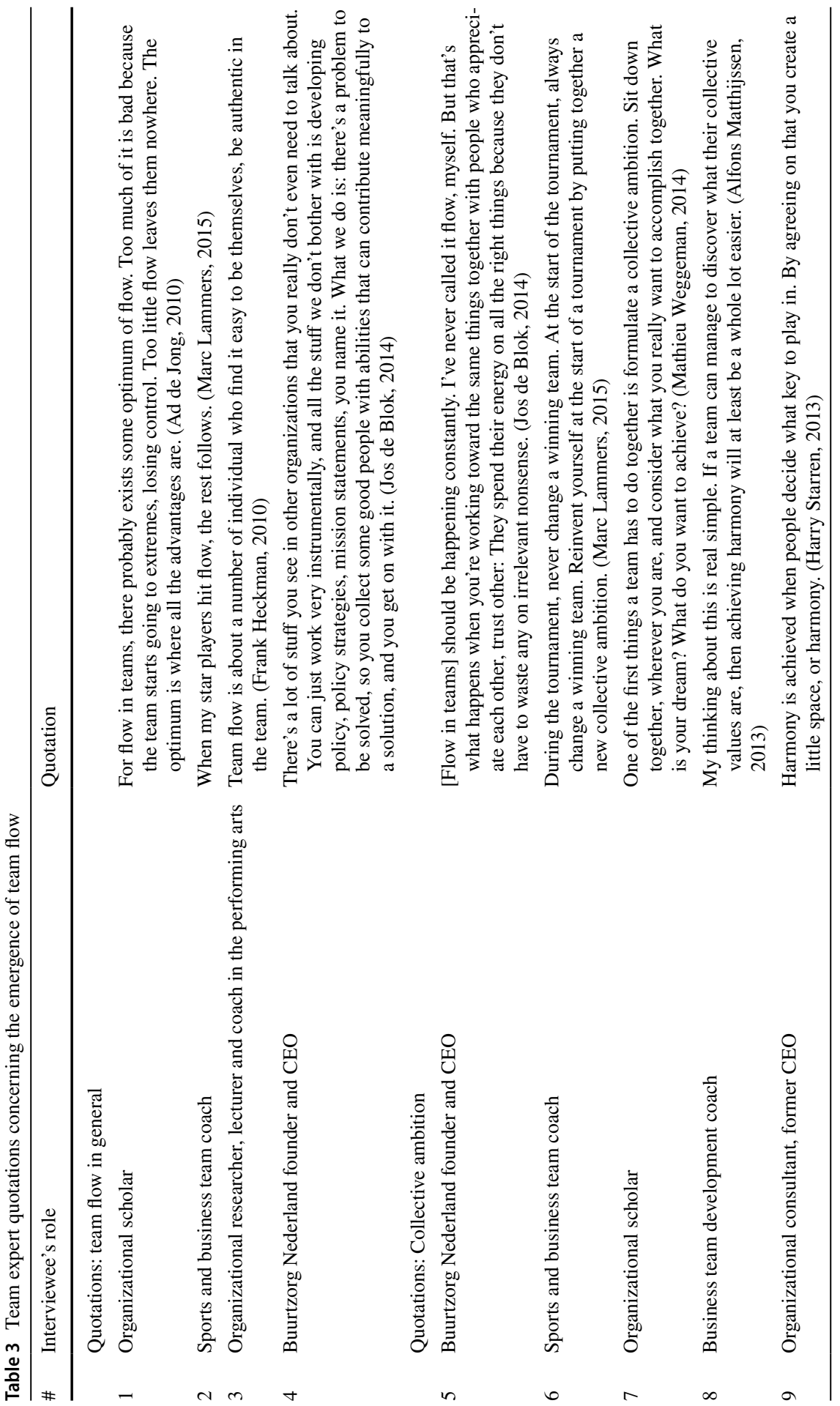




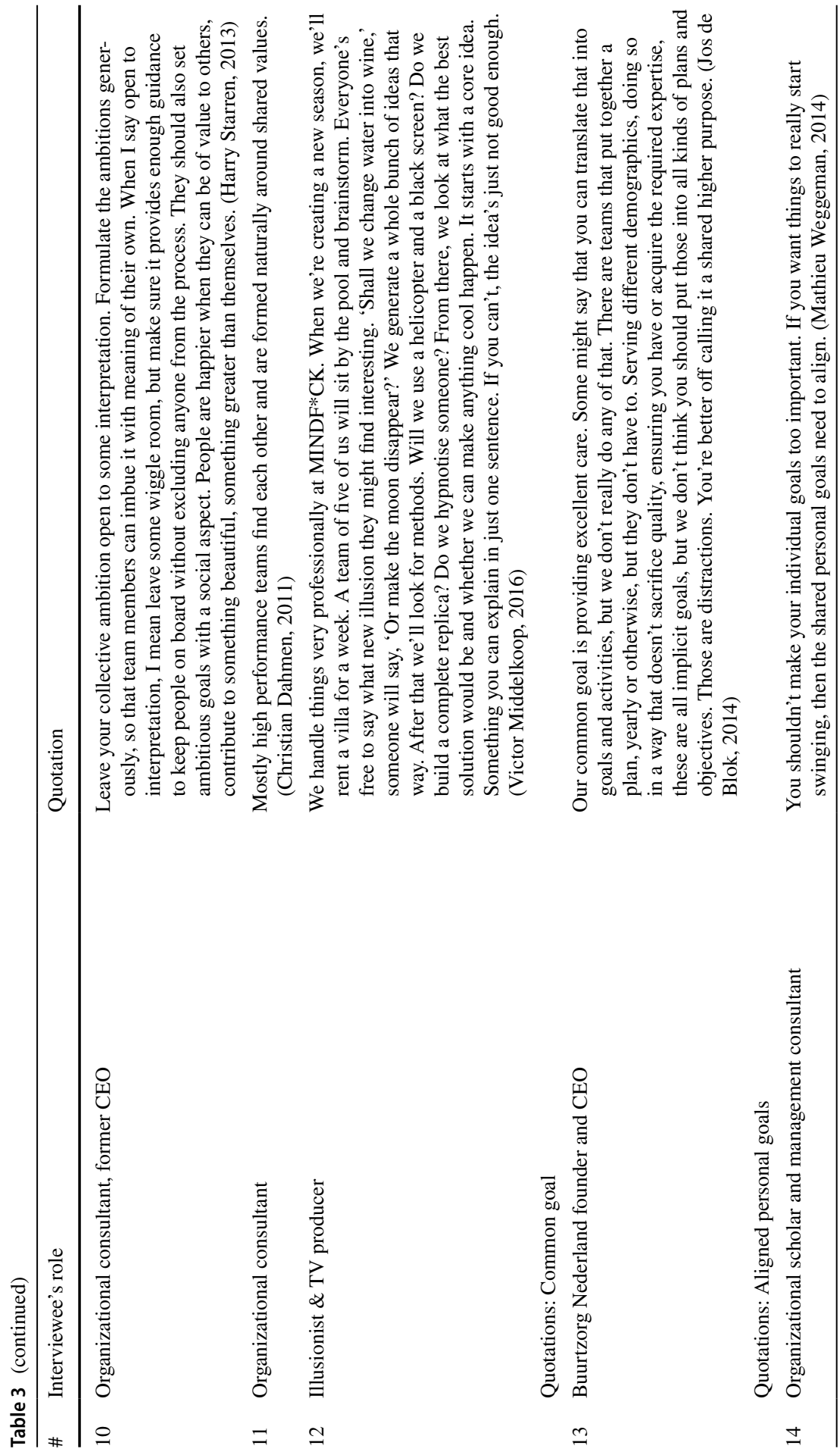




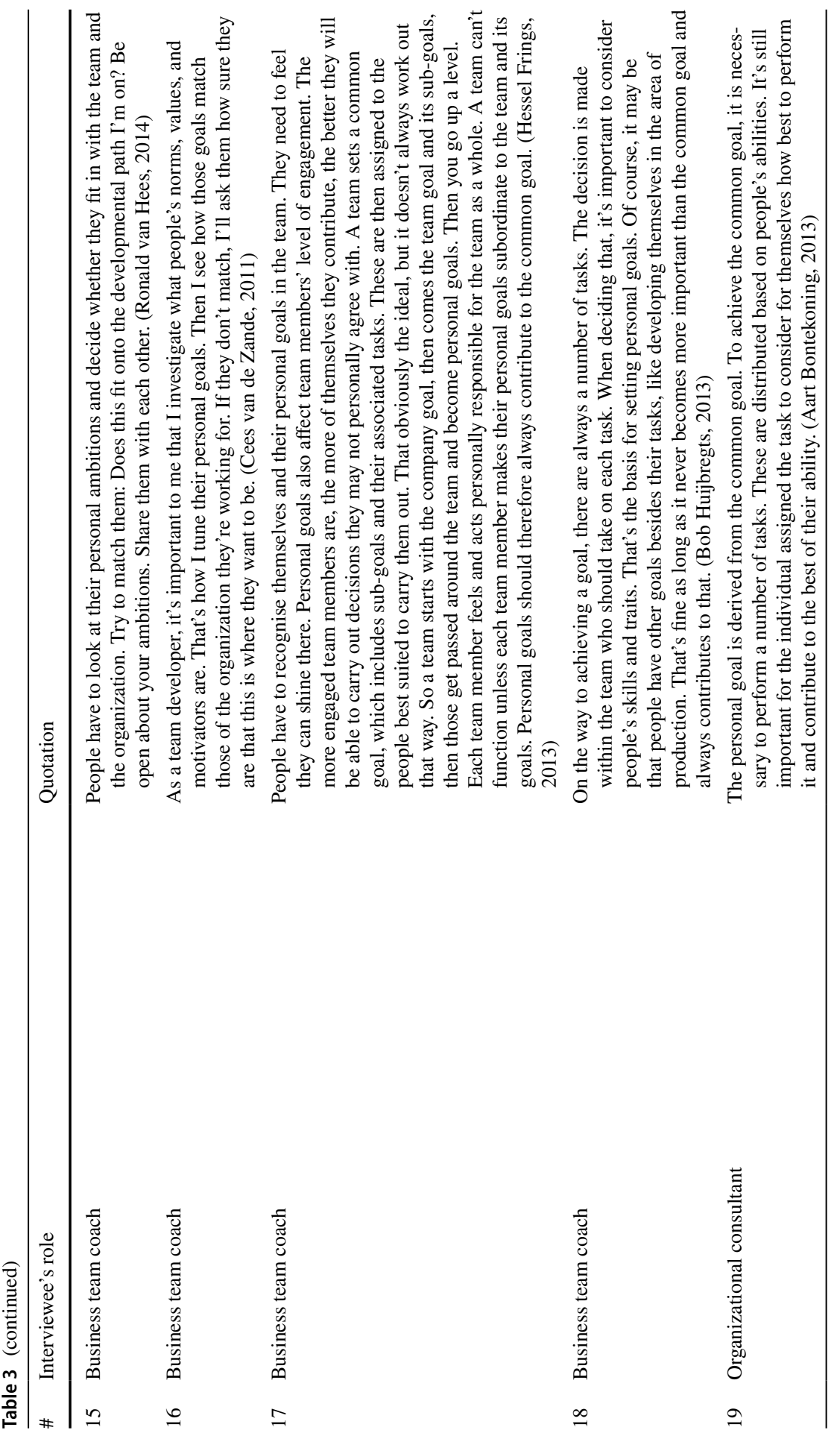




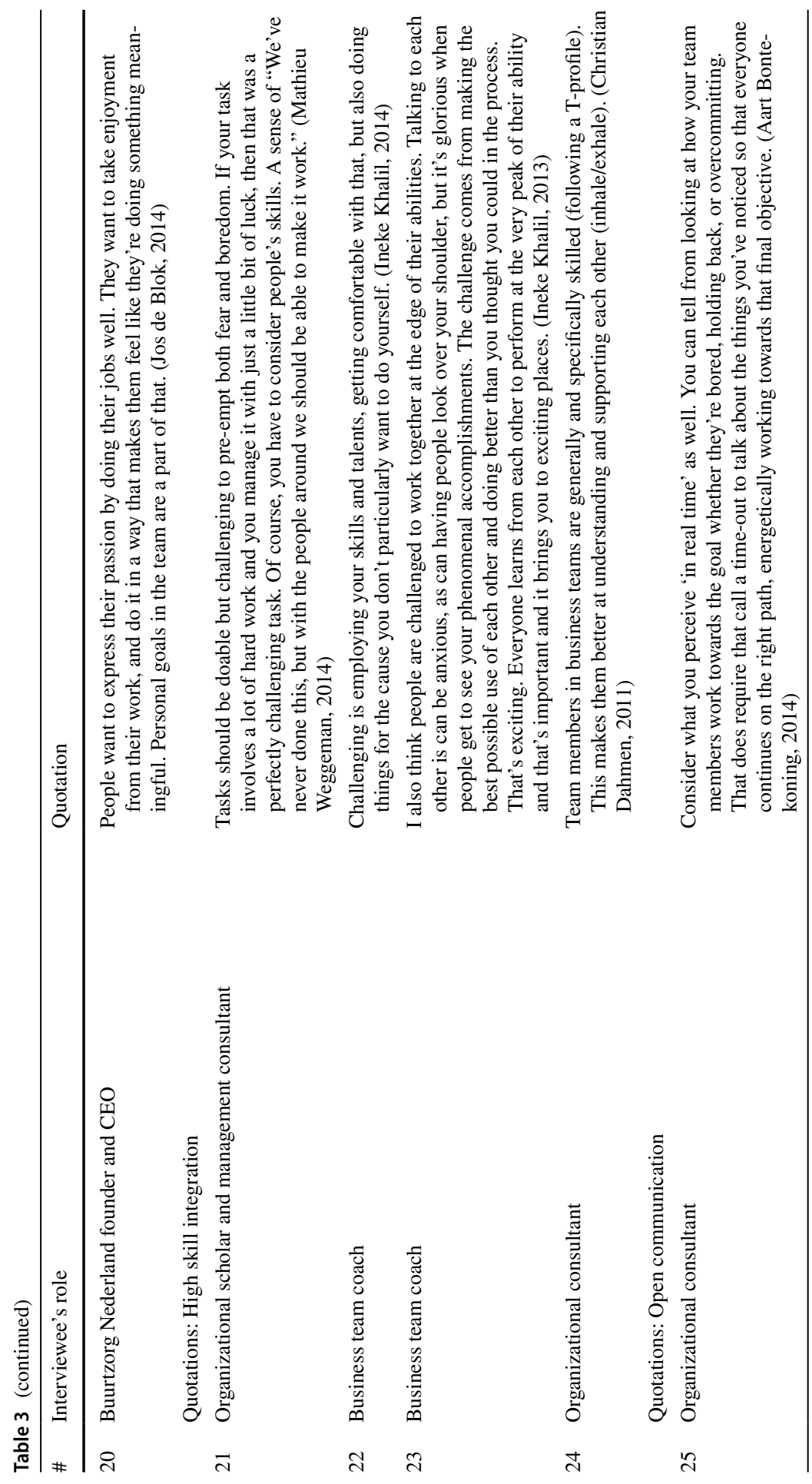




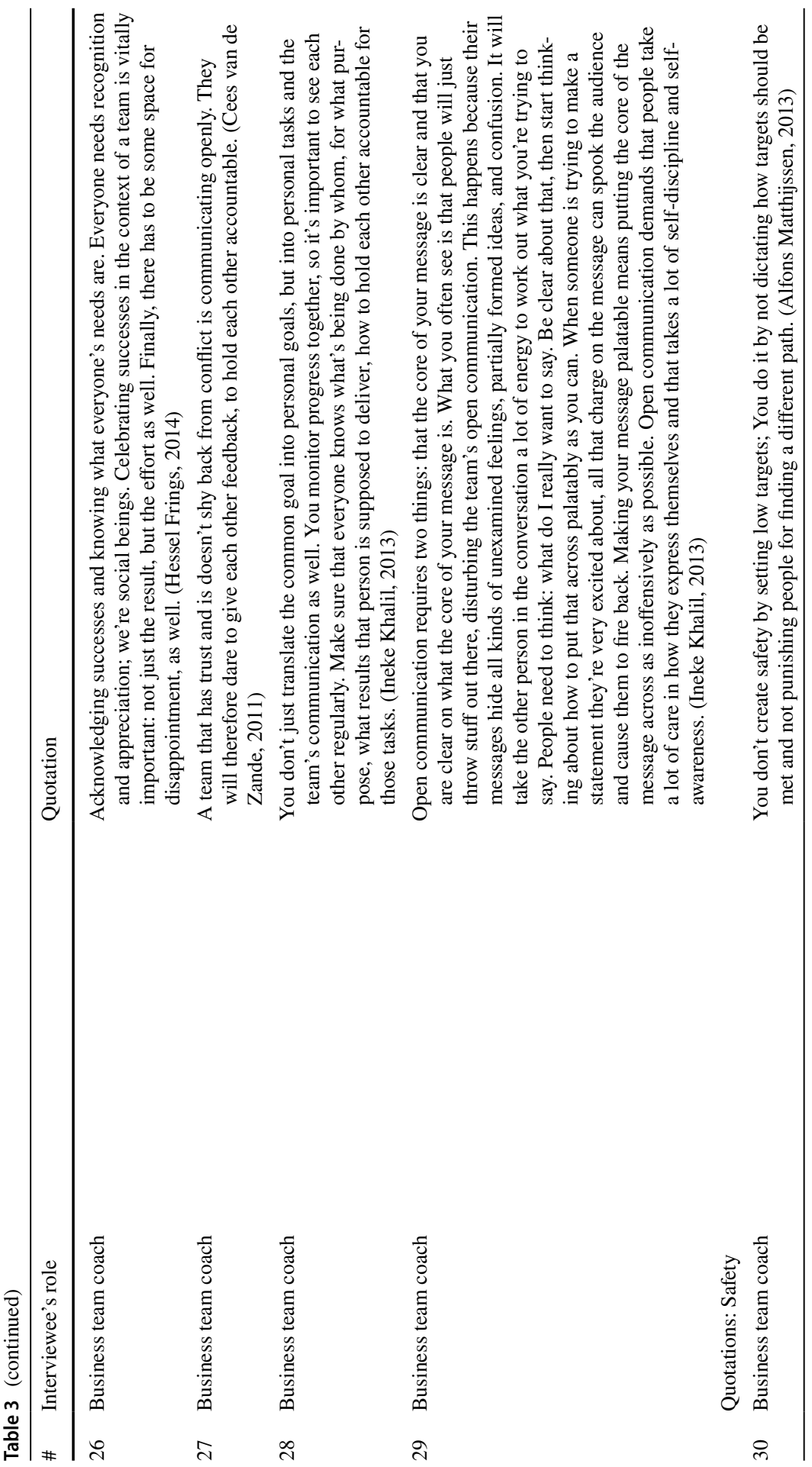




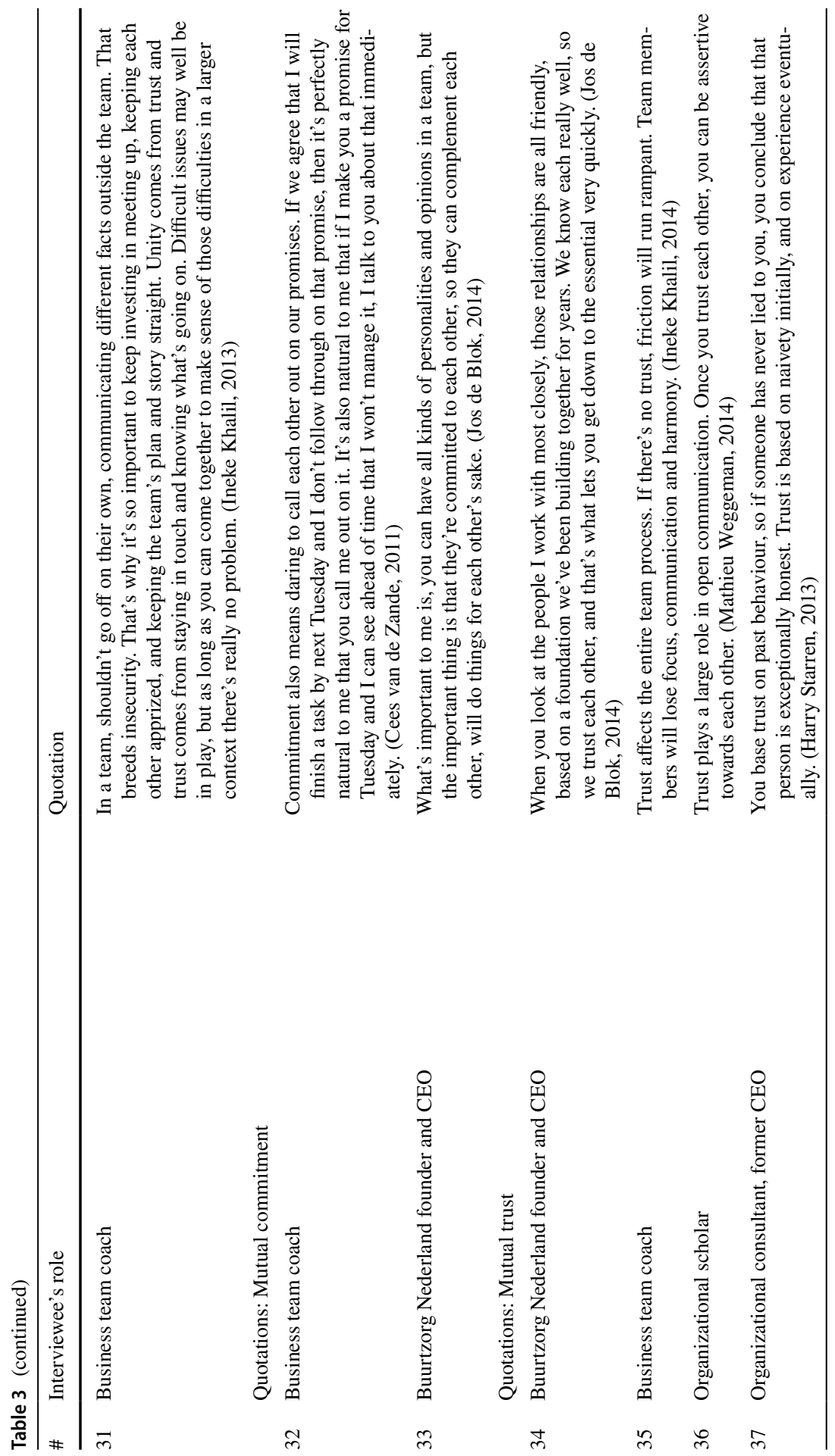




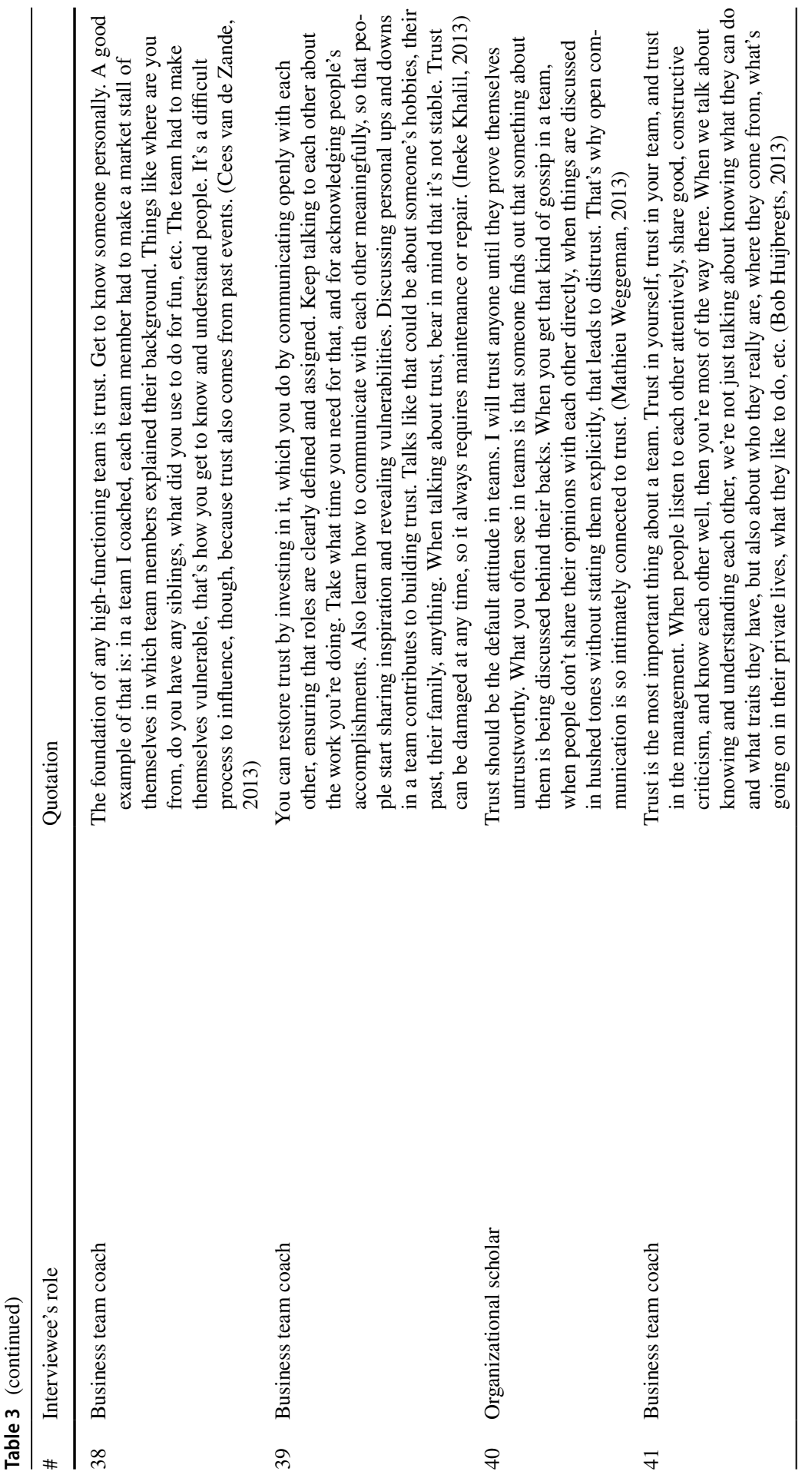




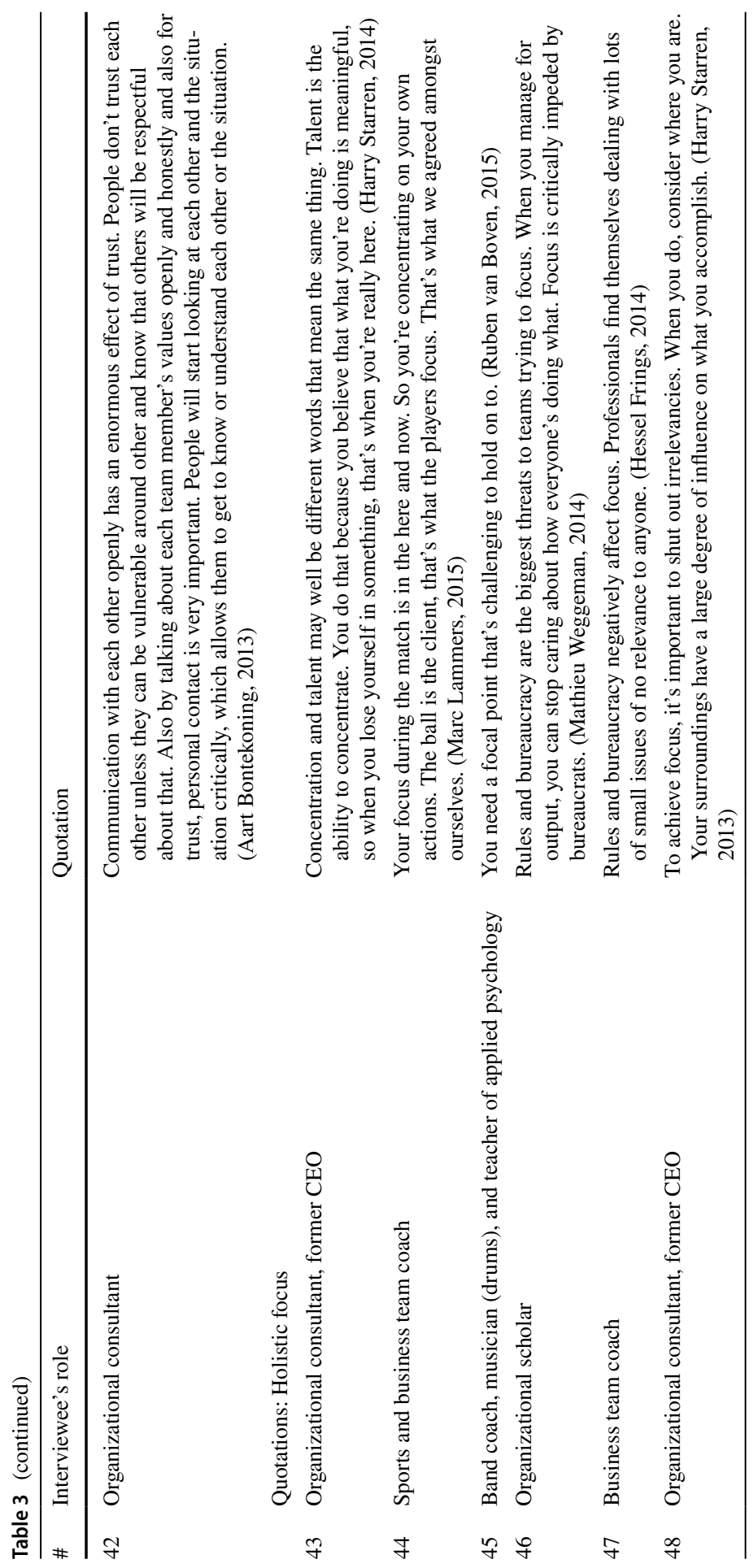




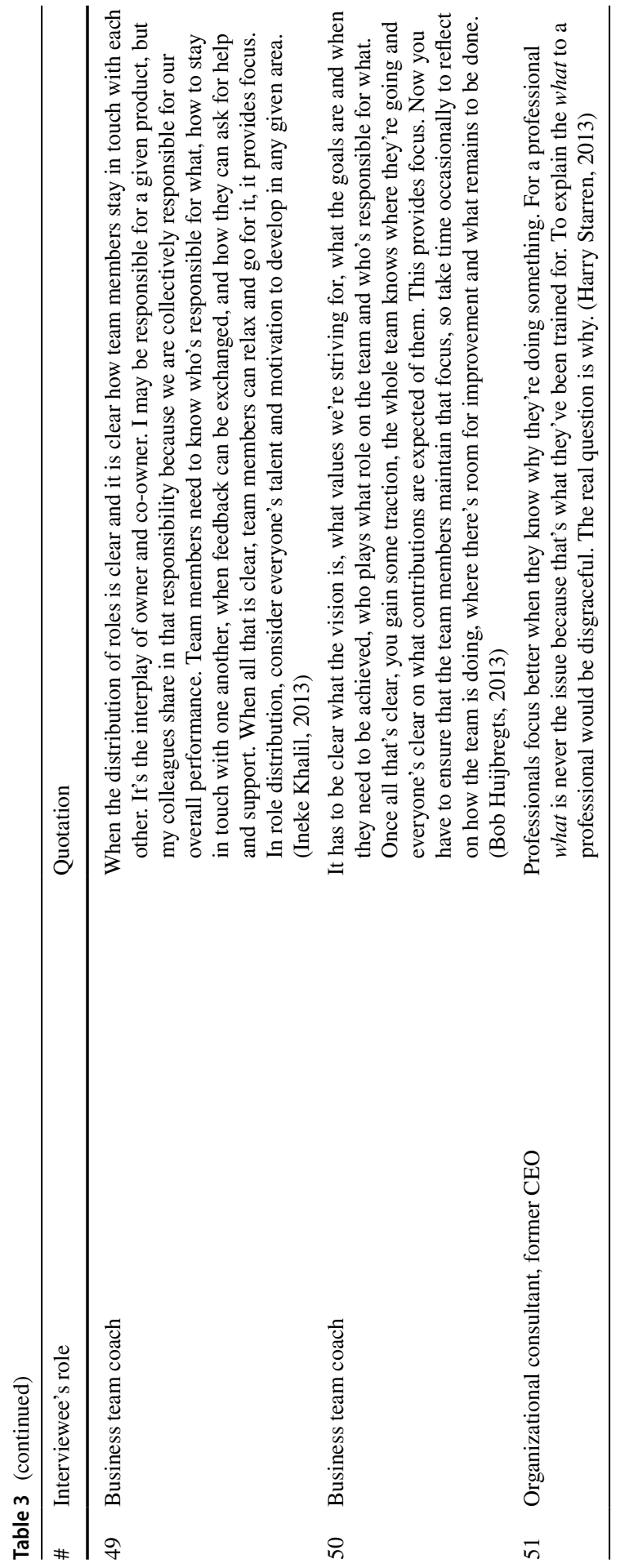


Table 4 Frequencies of impediments to team flow in the online surveys

\begin{tabular}{|c|c|c|c|c|c|}
\hline \multicolumn{2}{|c|}{ Q1: why do you NOT experience team flow? } & \multirow{2}{*}{$\begin{array}{l}\text { Frequency } \\
\text { (3 raters) } \\
5\end{array}$} & \multirow{2}{*}{$\begin{array}{l}\% \text { of } \\
\text { inter- } \\
\text { viewees }\end{array}$} & \multirow{2}{*}{$\begin{array}{l}\text { Fre- } \\
\text { quency (2 } \\
\text { rates) }\end{array}$} & \multirow{2}{*}{$\begin{array}{l}\% \text { of } \\
\begin{array}{l}\text { Inter- } \\
\text { viewees }\end{array} \\
13\end{array}$} \\
\hline Motivational issues & $\begin{array}{l}\text { Personal disengagement with the } \\
\text { task }\end{array}$ & & & & \\
\hline & Coworker laxity/negligence & 5 & 2 & 8 & 3 \\
\hline \multirow[t]{5}{*}{ Interpersonal issues } & Negativity & 9 & 4 & 23 & 10 \\
\hline & Disagreement/conflict & 0 & 0 & 5 & 2 \\
\hline & Miscommunication & 18 & 8 & 27 & 12 \\
\hline & Distrust & 3 & 1 & 8 & 3 \\
\hline & Lack of psychological safety & 4 & 2 & 5 & 2 \\
\hline \multirow[t]{5}{*}{ Task-related issues } & Disorganization & 9 & 4 & 21 & 9 \\
\hline & Work pressure/stress & 8 & 3 & 13 & 6 \\
\hline & Minimal challenge & 1 & 0 & 4 & 2 \\
\hline & Distractions & 11 & 5 & 11 & 5 \\
\hline & Bureaucuracy & 2 & 1 & 9 & 4 \\
\hline \multirow[t]{3}{*}{ Directional issues } & Unclear mission/vision & 6 & 3 & 10 & 4 \\
\hline & Inadequate leadership & 2 & 1 & 7 & 3 \\
\hline & Additional elements & 4 & 2 & 23 & 10 \\
\hline
\end{tabular}

$\mathrm{N}=231$, Fleiss $\kappa$ 


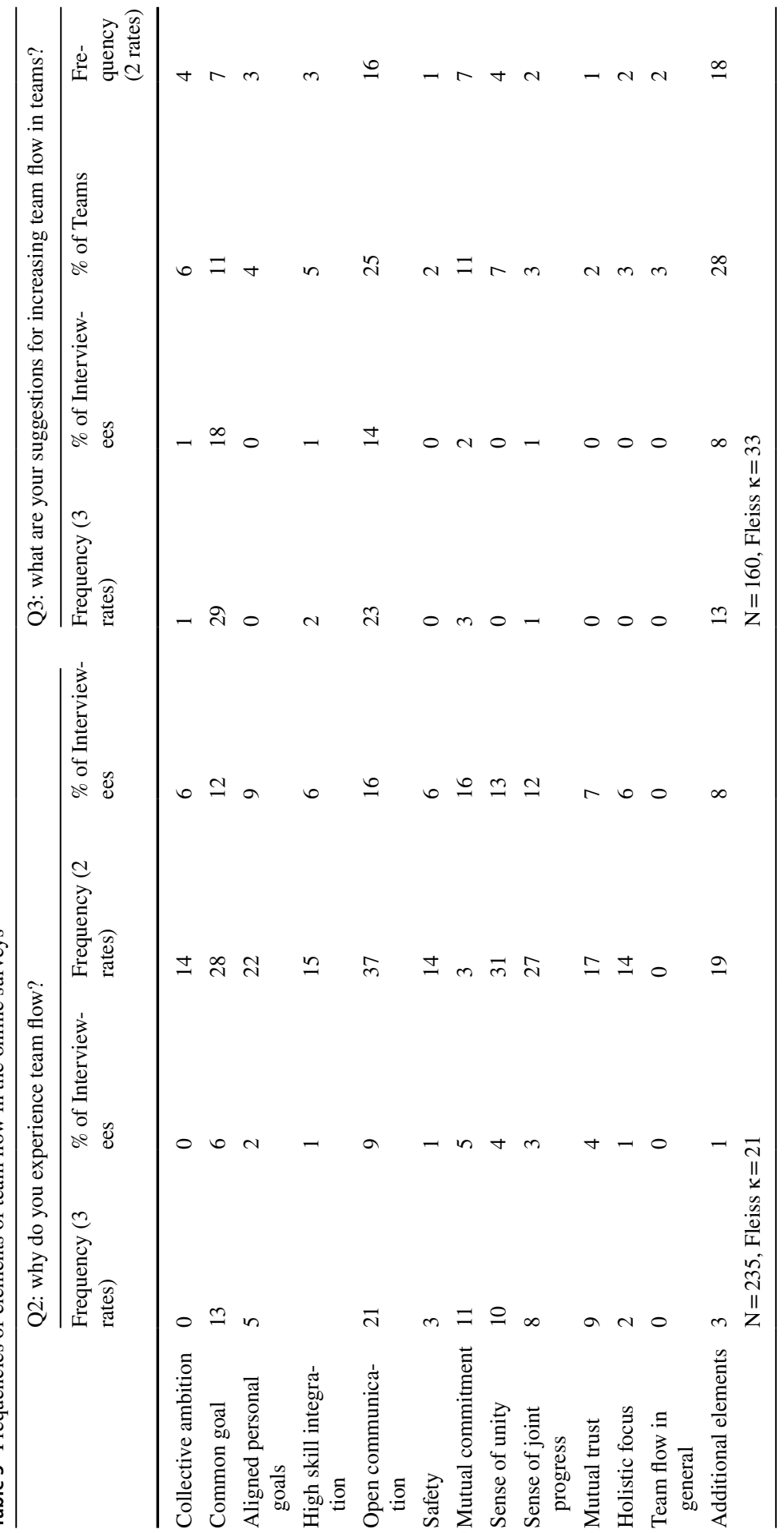




\section{Funding None.}

\section{Declarations}

Conflict of interest All authors declare that they have no conflict of interest.

Availability of data and material The data that support the findings of this study are available from the corresponding author upon reasonable request.

\section{Code availability N/A.}

Open Access This article is licensed under a Creative Commons Attribution 4.0 International License, which permits use, sharing, adaptation, distribution and reproduction in any medium or format, as long as you give appropriate credit to the original author(s) and the source, provide a link to the Creative Commons licence, and indicate if changes were made. The images or other third party material in this article are included in the article's Creative Commons licence, unless indicated otherwise in a credit line to the material. If material is not included in the article's Creative Commons licence and your intended use is not permitted by statutory regulation or exceeds the permitted use, you will need to obtain permission directly from the copyright holder. To view a copy of this licence, visit http://creativecommons.org/licen ses/by/4.0/.

\section{References}

Abuhamdeh, S., \& Csikszentmihalyi, M. (2009). Intrinsic and extrinsic motivational orientations in the competitive context: An examination of person-situation interactions. Journal of Personality, 77(5), 1615-1635.

Amabile, T. M., \& Kramer, S. J. (2011). The Progress Principle: Using Small Wins to Ignite Joy, Engagement, and Creativity at Work. Harvard Business Review Press.

Amason, A. C., \& Sapienza, H. J. (1997). The effects of top management team size and interaction norms on cognitive and affective conflict. Journal of Management, 23(4), 495-516.

Bardram, J. E., \& Hansen, T. R. (2010). Context-based workplace awareness. Computer Supported Cooperative Work (CSCW), 19(2), 105-138.

Ceja, L., \& Navarro, J. (2011). Dynamic patterns of flow in the workplace: Characterizing within-individual variability using a complexity science approach. Journal of Organizational Behavior, 32(4), 627-651. https://doi.org/10.1002/job.747

Charmaz, K. (2014). Constructing Grounded Theory. Sage.

Csikszentmihalyi, M. (1990). Flow: The Psychology of Optimal Experience. Harper and Row.

Csikszentmihalyi, M. (1996). Creativity: Flow and The Psychology of Discovery and Invention. HarperCollins.

Csikszentmihalyi, M. (1997). Finding Flow: The Psychology of Engagement with Everyday Life. Basic Books.

Csikszentmihalyi, M., Abuhamdeh, S., \& Nakamura, J. (2005). Flow. In A. J. Elliot \& C. S. Dweck (Eds.), Handbook of Competence and Motivation (pp. 598-608). Guilford Publications.

Culbertson, S. S., Fullagar, C. J., Simmons, M. J., \& Zhu, M. (2015). Contagious flow: Antecedents and consequences of optimal experience in the classroom. Journal of Management Education., 39(3), 319-349. https://doi.org/10.1177/1052562914545336

Davis, O. C. (2010). Defining microflow through the context of a waiting paradigm. Dissertation: Claremont Graduate University.

Dourish, P., \& Bellotti, V. (1992). Awareness and coordination in shared workspaces. Proceedings of the 1992 ACM conference on Computer-supported cooperative work. (pp. 107-114).

Edmondson, A. (1999). Psychological safety and learning behavior in work teams. Administrative Science Quarterly, 44(2), 350.

Glaser, B. (1978). Theoretical Sensitivity: Advances in the Methodology of Grounded Theory. The Sociology Press. 
Glaser, B., \& Strauss, A. (1967). The Discovery of Grounded Theory: Strategies for Qualitative Research. Aldine Transaction.

Gully, S. M., Incalcaterra, K. A., Joshi, A., \& Matthew, J. (2002). A meta-analysis of team-efficacy, potency, and performance: Interdependence and level of analysis as moderators of observed relationships. Journal of Applied Psychology, 87(5), 819-832.

Guzzo, R. A., \& Dickson, M. W. (1996). Teams in organizations: Recent research on performance and effectiveness. Annual Review of Psychology, 47(1), 307-338.

Guzzo, R. A., \& Salas, E. (1995). Team Effectiveness and Decision Making in Organizations. Jossey-Bass.

Guzzo, R. A., Yost, P. R., Campbell, R. J., \& Shea, G. P. (1993). Potency in groups: Articulating a construct. British Journal of Social Psychology, 32(1), 87-106.

Hackman, J. R., \& Wageman, R. (2005). A theory of team coaching. The Academy of Management Review, 30(2), 269-287.

Haleblian, J., \& Finkelstein, S. (1993). Top management team size, CEO dominance, and firm performance: The moderating roles of environmental turbulence and discretion. Academy of Management Journal, 36(4), 844-863.

Hamilton, E., \& Hurford, A. (2007). Combining collaborative workspaces with tablet computing: Research in learner engagement and conditions of flow. Proceedings of ASEE/IEEE Frontiers in Education Conference, Milwaukee, WI, Session, T3C, 3-8.

Hetland, A., Vittersø, J., Wie, S. O. B., Kjelstrup, E., Mittner, M., \& Dahl, T. I. (2018). Skiing and thinking about it: Moment-to-moment and retrospective analysis of emotions in an extreme sport. Frontiers in Psychology. https://doi.org/10.3389/fpsyg.2018.00971

Isaksen, S. G., \& Lauer, K. J. (2002). The climate for creativity and change in teams. Creativity and Innovation Management, 11(1), 74-86.

Katzenbach, J. R., \& Smith, D. K. (1992). The Wisdom of Teams: Creating the High-Performance Organization. Harvard Business Press.

Katzenbach, J. R., \& Smith, D. K. (1993). The discipline of teams. Harvard Business Review, 71(2), 111-120.

Landhäußer, A., \& Keller, J. (2012). Flow and its affective, cognitive, and performance-related consequences. In S. Engeser (Ed.), Advances in Flow Research (pp. 65-85). Springer.

Lee, T. W., Mitchell, T. R., \& Sablynski, C. J. (1999). Qualitative research in organizational and vocational psychology, 1979-1999. Journal of Vocational Behavior, 55(2), 161-187.

Locke, K. (2001). Grounded theory in management research. London: SAGE Publications, Ltd.

Locke, E., \& Latham, G. P. (2006). New directions in goal-setting theory. Current Directions in Psychological Science, 15(5), 265-268.

Mayer, R. C., Davis, J. H., \& Schoorman, F. D. (1995). An integrative model of organizational trust. Academy of Management Review, 20(3), 709-734.

Morse, J. M. (1994). Emerging from the data: The cognitive processes of analysis in qualitative inquiry. Critical Issues in Qualitative Research Methods, 346, 350-351.

Nakamura, J., \& Csikszentmihalyi, M. (2002). The concept of flow. In C. R. Snyder \& S. J. Lopez (Eds.), Handbook of Positive Psychology (pp. 89-105). Oxford University Press.

Nakamura, J., \& Csikszentmihalyi, M. (2009). Flow theory and research. In C. R. Snyder \& S. J. Lopez (Eds.), The Oxford handbook of Positive Psychology (2nd ed., pp. 195-206). Oxford University Press.

Obukhova, L. F., \& Korepanova, I. A. (2009). The zone of proximal development: A spatiotemporal model. Journal of Russian \& East European Psychology, 47(6), 25-47. https://doi.org/10.2753/RPO10610405470602

O’Leary-Kelly, A. M., Martocchio, J. J., \& Frink, D. D. (1994). A Review of the influence of group goals on group performance. Academy of Management Journal, 37(5), 1285-1301. 455.

Pels, F., Kleinert, J., \& Mennigen, F. (2018). Group flow: A scoping review of definitions, theoretical approaches, measures and findings. PLOS ONE, 13(12), e0210117. https://doi.org/10.1371/journal. pone. 0210117

Salas, E., Cooke, N. J., \& Rosen, M. A. (2008). On teams, teamwork, and team performance: Discoveries and developments. Human Factors: THe Journal of the Human Factors and Ergonomics Society, 50(3), 540-547.

Sato, I. (1988). Bosozoku: Flow in Japanese motorcycle gangs. In M. Csikszentmihalyi \& I. Csikszentmihalyi (Eds.), Optimal Experience: Psychological Studies of Flow in Consciousness (pp. 92-117). Cambridge University Press.

Sawyer, R. K. (2007). Group Genius: The Creative Power of Collaboration. Basic Books. 
Schmidt, K. (2002). The problem with 'awareness': Introductory remarks on awareness in CSCW'.' Computer Supported Cooperative Work (CSCW), 11(3-4), 285-298.

Schüler, J. (2012). The dark side of the moon. In S. Engeser (Ed.), Advances in Flow Research (pp. 123137). Springer.

Snow, K. Y. (2010). Work relationships that flow: Examining the interpersonal flow experience, knowledge sharing, and organizational commitment. (Doctoral Dissertation). Claremont Graduate University. Retrieved from http://gradworks.umi.com/34/36/3436590.html

Turner, B. A. (1981). Some practical aspects of qualitative data analysis: One way of organizing the cognitive processes associated with the generation of grounded theory. Quality and Quantity, 15(3), 225-247.

Van den Hout, J. J. J. (2016). Team flow: from concept to application. (Doctoral Dissertation). Eindhoven University of Technology, Eindhoven.

Van den Hout, J. J. J., \& Davis, O. C. (2018). The conceptualization of team flow. The Journal of Psychology: Interdisciplinary and Applied, 152(6), 388-423.

Van den Hout, J. J. J., \& Davis, O. C. (2019). Team Flow: The Psychology of Optimal Collaboration. Springer International Publishing.

Van den Hout, J. J. J., \& Davis, O. C. (2021). Flow. In V. P. Glăveanu (Ed.), The Palgrave Encyclopedia of the Possible (pp. 196-210). Cham: Palgrave Macmillan. https://doi.org/10.1007/978-3-319-98390-5

Van den Hout, J. J. J., Davis, O. C., \& Walrave, B. (2016). The application of team flow theory. In L. Harmat, F. Ø. Andersen, F. Ullén, J. Wright, \& G. Sadlo (Eds.), Flow Experience (pp. 233-247). Springer International Publishing.

Van den Hout, J. J. J., Davis, O. C., \& Weggeman, M. C. D. P. (2018). The conceptualization of team flow. The Journal of Psychology: Interdisciplinary and Applied, 152(6), 388-423.

Van den Hout, J. J. J., Gevers, J. M. P., Davis, O. C., \& Weggeman, M. C. D. P. (2017). Overcoming impediments to team flow. Challenging Organizations and Society, 6(2), 1165-1181.

Van den Hout, J. J. J., Gevers, J. M. P., Davis, O. C., \& Weggeman, M. C. D. P. (2019). Developing and testing the team flow monitor. Cogent Psychology, 6, 1. https://doi.org/10.1080/23311908.2019.1643962

Vaughan, D. (1992). Theory elaboration: The heuristics of case analysis. In C. C. Ragin \& H. S. Becker (Eds.), What Is a Case? Exploring the Foundations of Social Inquiry (pp. 173-202). Cambridge University Press.

Widmeyer, W. N., Brawley, L. R., \& Carron, A. V. (1986). Measurement of cohesion in sport teams: The Group Environment Questionnaire. Sports Dynamics, 14(1), 55-59.

Yin, R. K. (1994). Case Study Research: Design and Methods. Sage.

Publisher's Note Springer Nature remains neutral with regard to jurisdictional claims in published maps and institutional affiliations. 